\title{
Attendance Boundary Policies and the Limits to Combating School Segregation*
}

\author{
Andreas Bjerre-Nielsen ${ }^{\dagger} \&$ Mikkel Høst Gandil ${ }^{\ddagger}$ \\ First version: January 29, 2020. \\ This version: October 15, 2021
}

\begin{abstract}
What is the efficacy of redrawing school attendance boundaries as a desegregation policy? To provide causal evidence on this question we employ novel data with unprecedented detail on the universe of Danish children and exploit changes in attendance boundaries over time. Households defy reassignments to schools with lower socioeconomic status. There is a strong social gradient in defiance, as resourceful households are more sensitive to the student composition of schools. We simulate reassignments and find that boundary changes are ineffective in altering the socioeconomic composition of disadvantaged schools in highly segregated areas.
\end{abstract}

JEL Codes: H75,I21,I24,J18,R23

Keywords: School Segregation, Equality of Opportunity, Access to Education, Public School

\footnotetext{
*We wish to thank Julien Grenet, Edwin Leuven, Chris Neilson, Niels Johannesen, Hans H. Sievertsen, Benjamin L. Serena, Adam Sheridan, Mette Ejrnæs, as well as seminar participants at DGPE, Danish Economic Society Meeting, Copenhagen Education Network, Aarhus, and participants at the 8th European Meeting of the Urban Economics Association for helpful comments. We gratefully acknowledge financial support from the Danish Economic Council of the Labour Movement (Arbejderbevægelsens Erhvervsråd) and the Danish Innovation Fund as well as the Center for Social Data Science at University of Copenhagen. The Norwegian Research Council funded this research under project no. 275906.

†University of Copenhagen, anbn@econ.ku.dk

†University of Oslo, mikkel.gandil@econ.uio.no
} 


\section{Introduction}

Across the developed world, policymakers redraw school attendance boundaries (SABs) to alter the socioeconomic and ethnic composition of schools. However, if households find their designated school unattractive they may have other options and can choose not to comply. Outside options, therefore, pose a threat to the efficacy of boundary changes as a policy tool to change student composition and decrease school segregation. In this paper, we analyze how families' school enrollment and relocation decisions are affected by changes in local school provision and the implied efficacy of boundary changes as a desegregation policy.

Attendance zones are arguably the most common approach to allocate students to schools. However, very little is known about how boundary changes work as a means to change student composition. The main obstacle to obtaining well-identified estimates of such behavioral responses can be attributed to two distinct challenges: a lack of comprehensive panel data and a lack of exogenous variation in school affiliation. To overcome the first challenge, we exploit a new data set with precise geographic information on both school boundaries and household residential locations for the universe of Danish children during the years 2008-2015. In contrast to previous studies, we observe all enrollment and relocation outcomes within an entire country without attrition. To overcome the second challenge, we exploit changes in attendance boundaries over time. Due to the boundary changes, some households will experience a change in school affiliation right before their child reaches schooling age while others will not. By comparing, within original attendance zones, those households who are reassigned to those who are not, we identify the effect of the school composition on primary school enrollment. The number of boundary changes is large. During our observed period, a total of 191 schools, 17 percent of all schools, have parts of their attendance reassigned to another school. We estimate the responses of households to school characteristics in a difference-in-difference design and find flat pre-trends, which gives credence to a causal interpretation of the estimated parameters as responses to school assignments. The number of changes, the comprehensiveness of our data, and the robustness of our research design allow us, to an unprecedented degree, to fully investigate heterogeneity in household responses both in terms of the magnitude of changes and as a function of socioeconomic characteristics of households.

We find large and immediate effects on households with children reaching school age that are transferred to schools with a lower average socioeconomic status. A one standard deviation drop in the average socioeconomic status (SES) of the school implies an average fall in initial school enrollment of 21 percent. We find qualitatively the same results when we replace schoolSES with the ethnic composition of students. ${ }^{1}$ When average school-SES is replaced by a publicly available measure of school value-added we only find weak systematic responses,

\footnotetext{
${ }^{1}$ We are unable to separate the effect of schools' average socioeconomic status from the ethnic composition as the two measures are highly correlated.
} 
implying that parents give more weight to socioeconomic factors of peers than school ability to lift students. We also provide evidence of a strong social gradient: the enrollment decision of the highest SES quartile is 2.2 times as sensitive to the student composition as that of the lowest quartile.

Households primarily avoid a new designated school by enrolling their children in other public schools - an option provided free of charge in Denmark. It is not clear that all households have equal access to other public schools outside the attendance zone as the admission process is opaque and decentralized. ${ }^{2}$ In the first year after the boundary change, we find some evidence that households choose a private school or move out of the attendance zone as a means of avoidance. When we investigate the responses of households with children, who are younger at the time of redrawn boundaries, and thus have more time for planning enrollment before reaching schooling age, we find indications of increased responses along the private school margin. Though these latter estimates are imprecise, we conjecture that the smaller effect on private school enrollment found in our main sample of school-age children may be due to the element of surprise of a boundary change and a lack of supply as private schools are oversubscribed. ${ }^{3}$ Using a boundary-discontinuity design we find a clear pattern of discontinuous use of private schools at the boundary, suggesting that this is an important exit margin. While strong assumptions are required for a causal interpretation of the estimates from the boundary-discontinuity design, they suggest that behavior along additional margins, while important in the long term, may not be fully captured by our main research design. Due to the possibility of implicit discrimination in the choice process and element of surprise in the boundary change, we are unable to directly identify preferences separate from admission constraints. Accordingly, our estimates reflect the combinations of these two factors. Fortunately, the reduced form policy response we identify is the one that school authorities would need to evaluate the short-term desirability of a boundary change. ${ }^{4}$

Our results imply that there are inefficacies to boundary changes as a means to change the socioeconomic composition of schools. To illustrate the magnitude of this inefficacy, we embed our results in a simple simulation of two schools and compute the first-order response for those directly reassigned. For a range of levels of residential segregation, we assign a random sample of parcels from one school to the other and quantify the expected responses of those transferred. When parcels are assigned from a less affluent school to a more affluent school, the increase in school-SES induces more households to comply with the assignment than what would be expected in the absence of behavioral responses to school composition. However,

\footnotetext{
${ }^{2}$ In an audit study, Olsen et al. (2020) find that such discrimination against applicants with Muslim names.

${ }^{3}$ Private schools often have waiting lists, requiring households to apply years in advance; the limited supply would narrow the feasible set of private schools. Likewise, relocating quickly can be expensive and infeasible (e.g. due to commuting and financial constraints) for households.

${ }^{4}$ However, effects might not be constant if the system is dramatically changed in ways that affect the access to outside options.
} 
such changes leave the composition of the low-SES school unchanged. In order to change the composition of the low-SES school, we simulate a reassignment of households from a high-SES to a low-SES school. If assigned to a school with one standard deviation lower school-SES, the resulting increase in the SES of the destination school (i.e. the less affluent school) is only 60 percent of the increase predicted by a model with constant compliance. ${ }^{5}$ For larger levels of initial socioeconomic segregation, the actual transfer of parcels deviates further from the expected level and for very large levels of segregation, the expected changes in school-SES fail to materialize entirely. Thus, in communities where desegregation may be most desirable, the simulations suggest that changing attendance boundaries to move affluent families to less affluent schools is not a viable policy tool.

To our knowledge, we are the first to examine how school provision resulting from boundary changes affects enrollment in the intended school. The most related paper to ours are Billings et al. (2014) and Billings et al. (2018). Billings et al. (2014) leverage boundary changes from a single reform to investigate consequences of reassignment on long-term educational attainment and criminal behavior. They examine enrollment behavior and "find little evidence of differential attendance by school type across the newly drawn boundaries". However, they do not directly measure enrollment in the newly assigned school but instead establish that intended change in the assignment of children correlates with actually experienced changes (though only imperfectly). ${ }^{6}$ Billings et al. (2014) choose to present reduced form estimates of effects of reassignment on outcomes and do not estimate a school effect with an Instrumental Variable (IV) estimator, explicitly noting the issue of possible avoidance. We precisely quantify such avoidance patterns and show that systematic defiance is a first-order issue. Heterogeneous school and peer effects are, therefore, not directly identifiable via IV in settings where households can opt out of the allocation system. Billings et al. (2018) investigate the importance of increased access to school choice following failures of local schools to meet educational standards. They find that high-SES household sort into areas with increased choice, but due to data limitations cannot condition on initial residential locations and therefore track residents across areas and schools. This fact that residential sorting indirectly affects enrollment by altering the choice sets is a motivation of our difference-in-difference design, which is not subject to attrition. We can therefore estimate effects for the population most-likely of interest, those living in a geographic area which experience the change in school affiliation. ${ }^{7}$

\footnotetext{
${ }^{5}$ These numbers reflect our preferred model with heterogeneous responses and under the assumption that the additional travel was on average 2 kilometers.

${ }^{6}$ They do, however, assess two indirect options of opting out: they find small effects on the use of public school schools with specialized curriculum among non-minority but no effect on relocation.

${ }^{7} \mathrm{We}$ employ precise measures at the individual and school level of socioeconomic status and ethnic background as well as public measures of school value-added measures. In addition, we track children and their families throughout any public or private school in Denmark, which means that attrition is not a concern. The systematic avoidance behavior is not only of interest to policy makers, it also renders estimates of school effects through Instrumental Variable approaches problematic as the avoidance behavior amount to breaking the monotonicity condition presented by Angrist et al. (1996). For example, a "negative" shock might induce parents to choose a
} 
Little empirical evidence exists on the behavioral responses to changes in school affiliation. The best well-identified behavioral responses to school composition are estimated in the context of court-ordered desegregation in the US by Baum-Snow and Lutz (2011). Desegregation of schools in the US has often been massive undertakings, reforming entire collections of districts. Baum-Snow and Lutz (2011) use this source of variation to measure aggregate effects over longer horizons on geographical units making it hard to disentangle residential sorting and enrollment responses. ${ }^{8}$ The context of court-ordered desegregation and the associated research differs markedly from our approach both in the methodological approach and in the understanding of desegregation. We investigate changes in boundaries and track individual-level responses at the onset of school age, in years immediately after district changes. This allows us to precisely disentangle different means of avoidance and the role of residential sorting. We define desegregation in our context as an effort to locally change the student composition by changing the eligible student pool marginally. Policymakers and school administrators are arguably more likely to be interested in the local effect that we measure as it reflects the actual desegregation tool at their disposal and will give them a more precise estimate of the effects.

Attendance zones are the most common way of allocating children to schools across the world. School systems that use attendance zones either exclusively or in combination with elements of school choice include among others the United States (Monarrez, 2021), China (OECD, 2016), France (Fack and Grenet, 2010; Hiller and Tercieux, 2013), Spain (Calsamiglia, 2013), Italy (Merlino and Nicoló, 2012), Scotland (Manlove, 2013) and Argentina (Chavez et al., 2012). Our findings are therefore directly relevant for administrators in school systems with attendance zone allocation in these countries. We show that the structure of the system for primary education matters; households exploit the options available to them. Thus, the more similar the system, the more directly transferable are the estimates to a given context. A prime candidate for comparison is France with a combination of a degree of choice in public schools and prevalence of relatively cheap private schools, see Fack and Grenet (2010); Hiller and Tercieux (2013). Several large school districts in the US also resembles the Danish system with attendance zones in combination with school choice and charter schools (Billings et al., 2014; Monarrez et al., 2020). Even in systems with less choice between public schools than Denmark, our results indicate that families will respond using other means such as private school enrollment or relocation. ${ }^{9}$

A broader literature on compliance with school assignments dates back to Coleman et al. (1966) report that defined the relocation of white people from urban to suburban areas as "white

more attractive school implying a "positive" treatment.

${ }^{8}$ Baum-Snow and Lutz (2011) uses census data measured each decade with fixed effects at the metropolitan area level.

${ }^{9}$ As a concrete example, Monarrez et al. (2020) show that the presence of charter schools directly affect school segregation. Unlike in the US, school funding does not differ between schools within municipalities. Thus we conjecture that our estimated effects may be larger if educational resources were positively correlated with the socioeconomic composition of students. 
flight". Subsequent work has sought to measure out-group avoidance in school enrollment (Rossell, 1975; Clotfelter, 1976; Saporito and Sohoni, 2007; Rangvid, 2009; Bifulco et al., 2009; Riedel et al., 2010) and has emphasized outside options of private schools (Clotfelter, 1976) and relocation (Baum-Snow and Lutz, 2011). Our findings are consistent with these findings in that households tend to avoid schools where the ethnic or socioeconomic composition of students differs from themselves. Our findings add to this literature by being more focused on policies and by using a clear identification strategy to handle bias from residential sorting.

A related but different procedure for assigning students to schools is to allow for 'school choice', i.e. where students express their priorities over schools and are assigned based on these. Since the seminal work of Abdulkadiroğlu and Sönmez (2003) an expanding literature has examined school choice from a theoretical perspective, but the system has also been adopted in some urban areas to allocate children schools, most notably in Boston. This framework has been used to analyze the possible implementations of political goals such as desegregation (Cantillon, 2017) by using quotas for specific sociodemographic groups (Abdulkadiroğlu and Sönmez, 2003; Ehlers et al., 2014; Echenique and Yenmez, 2015). Applied researchers have used applicant priorities over schools from truth-revealing assignment mechanism to estimate preferences for schools (Hastings et al., 2009; Burgess et al., 2015; Borghans et al., 2015; Abdulkadiroğlu et al., 2020). ${ }^{10}$ The general findings relevant for our analysis are that households prefer schools that are closer to home, schools with better test performance, and schools with higher average socioeconomic status (or a proxy thereof). The preferences for quality and socioeconomic composition are generally found to be increasing in households' own socioeconomic backgrounds.

One can see policies of redrawing boundaries as simply affecting the supply of schools for certain groups within the school choice framework. As a consequence, our results indicate that the introduction of quotas and similar measures that target how schools prioritize applicants will likely face reactions by applicants such as submitting altered preferences or possibly relocating or using private schools. Therefore, such school choice policies aimed at desegregation likely operate under similar participation constraints as those documented here. In fact, Bibler and Billings (2020) show that lottery losers in a school choice mechanism react by relocating to other school districts thereby incurring significant costs. Their findings complement ours by showing that outside options also are important for the efficacy of school choice policies. While they find evidence of relocation, we find evidence for the use of private schools and other public schools. This indicates that the choices available to applicants likely play a big role. While there is a large amount of research on school choice, actual allocation of students to schools is still predominantly done via attendance zones and our estimates reflect choices made under a more

\footnotetext{
${ }^{10} \mathrm{~A}$ research literature on preferences for schools uses surveys but it has largely been dismissed due to possible bias in reporting and a failure to account for different choice sets available to parents (Burgess et al., 2011).
} 
widely used mechanism.

Our paper also provides new insights to the literature on boundary discontinuity design, which leverages discrete changes in school characteristics at attendance boundaries to identify the impact of schools' composition and average test scores on house prices (Black, 1999; Kane et al., 2006; Bayer et al., 2007; Clapp et al., 2008; Fack and Grenet, 2010; Black and Devereux, 2011; Gibbons et al., 2013; Imberman and Lovenheim, 2016). We demonstrate novel dimensions of discontinuities by directly measuring enrollment outcomes across the boundaries, and through our event study design, we show that relocation, and thus real estate markets, only play a partial role in the behavioral responses to changes in school composition. Not accounting for other margins of defiance leads to an overestimation of the efficacy of redistricting. Further, we employ the boundary discontinuity design to document the presence of residential sorting around boundaries, which invalidates the boundary discontinuity design as an approach to identify responses of mobile households. This motivates our identification strategy which is based on within-origin attendance zone comparisons rather than boundary comparisons. In Section 5.4 we develop a combination of the boundary discontinuity design and our differencein-difference design to investigate spatial heterogeneity as a robustness check.

\section{Institutional background}

Danish children usually start primary school in the summer of the year they turn six. Municipalities run the public primary schools and decide on the level of funding on a municipal level. Public schools are free and parent co-payment is forbidden by law. There are extensive transfers between municipalities to combat inequality in funds attributable to differences in population composition and local tax revenue, therefore, does not completely determine available funds for schooling. Each municipality decides on the number of schools and attendance zones (or school districts) associated with these schools. Every residential address is associated with exactly one school, which we refer to as the district school. ${ }^{11}$ Children have a right to enroll in their district school and, once enrolled, a child is not affected by future district changes (with the exception of mergers and closures).The municipal council is free to choose its priorities when constructing the attendance zones. Changes in attendance zones are common and are often used as a way to manipulate student body characteristics, especially in large urban areas such as the Copenhagen metropolitan area, Aarhus and Odense. ${ }^{12}$

If parents do not want to comply with school assignments they have two options: other public schools with spare capacity or a private school. Parents can enroll their child in other public schools than the district school free of charge if the desired school has "sufficient capacity".

\footnotetext{
${ }^{11}$ These attendance zones are called districts. Each district has one school; thus there is no distinction between attendance zones and school districts in Denmark.

${ }^{12}$ We interviewed the responsible administrators in the municipality of Copenhagen and consulted administrative texts to verify this to be the case.
} 
This is usually defined by a cap on class size and the total number of pupils in a school. ${ }^{13}$ The process is decentralized and with practically no reporting requirements. Thus, little is known about the fairness and legality of the process by which children from outside the attendance boundary are prioritized for admission. Children can change school during the school year if the desired school has sufficient capacity. This creates the possibility that an initially oversubscribed school may become accessible for outside-district children if an already enrolled child moves away. ${ }^{14}$

The other margin by which parents may defy school assignments is private school enrollment. Private primary schools are prevalent in Denmark. Around 42 percent of children aged 7 have a private school within $2 \mathrm{~km}$ of their home and 85 percent have one within $10 \mathrm{~km}$, see Figure B.1a in the appendix for the full distribution. Private schools are non-profit and receive funds from the government covering on average 75 percent of the average cost of a pupil in public school. Parents cover additional costs. Danish private schools are free to set their own price, and parents typically pay 130-270 euros a month per child with possible discounts for siblings. ${ }^{15}$ Private schools choose who to admit and thus have no attendance zones. Popular private schools have waiting lists and parents can sign up their children up early in the life of their child. Anecdotal evidence suggests that private schools, especially in urban areas, tend to be vastly oversubscribed. Parents, therefore, cannot be sure to exploit private schools as an alternative to the district schools, as enrollment is contingent on being on a waiting list and being admitted. The overall enrollment in private schools increased from around 12.5 pct. in 2007 to 16.4 in 2016. The increase was mainly driven by rural areas, see Figures B.1b and B.1c in the appendix.

Changes in attendance boundaries The administrative procedures of changing attendance boundaries differ between Danish municipalities. The changes are usually announced no more than a year before they occur, usually in the spring before the beginning of the school year in August. Proposals for changes are usually made by administrative staff of the municipalities and are subject to confirmation by the elected municipality council. The changes most often

\footnotetext{
${ }^{13}$ The municipality can delegate to the school principal the authority to suspend the right of outside-district children to be admitted to a certain class or year in a school. Generally, a school class must not exceed 28 at the beginning of the school year, although under special circumstances the municipality council can allow classes to reach a maximum of 30. The municipality can decide on a separate class size limit for which pupils from outside the school attendance zone can no longer enter. If a school receives more applications than its capacity, then the children outside the attendance zone should be admitted according to objective criteria. The Danish Ministry of education recommends distance and sibling preference as a criterion. See guidelines on the Danish school choice system https://www.uvm.dk/folkeskolen/fag-timetal-og-overgange/skolestart-og-boernehaveklassen/frit-skolevalg.

${ }^{14}$ The chance of admission, therefore, depends on the timing of the request to move. It is, therefore, possible for parents to increase the opportunities for admission by repeatedly contacting the desired school. We cannot follow this process in our data.

${ }^{15}$ We have been unable to locate a central registry of prices of private schools, and our estimates are therefore based on data collected on the webpage of the private schools association; https://privateskoler.dk/ skolerne/liste-over-skolerne.
} 
occur due to changing demographics which induce shifts in the demand for primary schooling. ${ }^{16}$

To illustrate such boundary changes, we briefly describe the example of the municipality of Hvidovre located in the Copenhagen metropolitan area with approximately fifty-thousand residents. The two maps in Figure 1 illustrate how the attendance boundaries were redrawn between 2008 and 2009. Areas that were transferred between schools are shown in solid lines in Figure 1b. The remaining areas experienced no change in school affiliation. A white paper from the municipality illustrates the argument for such changes: "In addition to being able to solve the capacity challenges, a school structure change must also take into account the unequal distribution of students with respect to weak and strong socioeconomic background. [...] Therefore, it is absolutely central to consider a diverse student composition in addition to solving the capacity challenges" (Hvidovre, 2019). In other words, while capacity management is a central focus, so is the socioeconomic composition of schools.

\section{Data and measurements}

Our analysis is based on Danish registry data for the years 2008-2015. ${ }^{17}$ From Statistics Denmark we obtain detailed information on household income, education, ethnicity, and school enrollment. We link these records to detailed geographical information on over 95 percent of households in Denmark. ${ }^{18}$ The median geographic unit has a size of 0.08 square kilometers with larger precision in dense urban areas. We obtain attendance zone data from records in the CPR-vej-register. These are reported by the municipalities themselves and are not verified by Statistics Denmark. ${ }^{19}$

\footnotetext{
${ }^{16}$ We have interviewed responsible authorities in the municipality of Copenhagen as well as gone through public documents from other municipalities to understand the process. When a proposal of a change is made, citizens and schools may voice concerns, which sometimes turns into heightened, local political tension. Therefore, enacted changes in this context might not be completely random as some areas are likely more difficult politically to manipulate due to a politically strong citizenry. Anecdotal evidence suggests this is mostly due to the closing of schools as opposed to tiny changes around boundaries. In order to ensure exogeneity, we focus on transfers between existing schools. We exclude mergers and closings of schools by requiring that both schools involved in an exchange exist before and after a recorded change in school affiliation. To further validate our design we perform balancing tests in Subsection 5.4

${ }^{17}$ The data go further back but the data quality on addresses, and thus geographic data, suffers from a break in 2007 when Denmark implemented a large reform of municipalities.

${ }^{18}$ We have constructed a set of polygons such that the k-anonymity of the households is maintained, see BjerreNielsen and Gandil (2018) for details. Software is available at GitHub; https ://github.com/abjer/private_ spatial_dk.

${ }^{19}$ For structuring data we have made extensive use of open-source Python libraries. Among others we have used Pandas, Scipy, Scikit-learn, and NetworkX for data structuring, see McKinney (2010); Jones et al. (2001-); Pedregosa et al. (2012); Hagberg et al. (2008); GeoPandas, and Shapely for GIS-data manipulation, see Gillies et al. (2007-); Matplotlib for plotting. For all regression we use StataCorp (2017).
} 


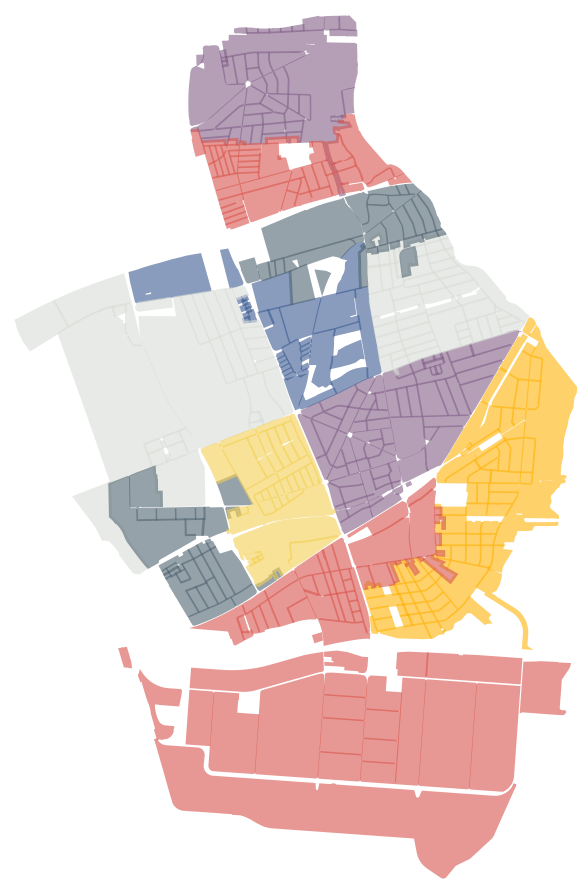

(a) Attendance zones in 2008

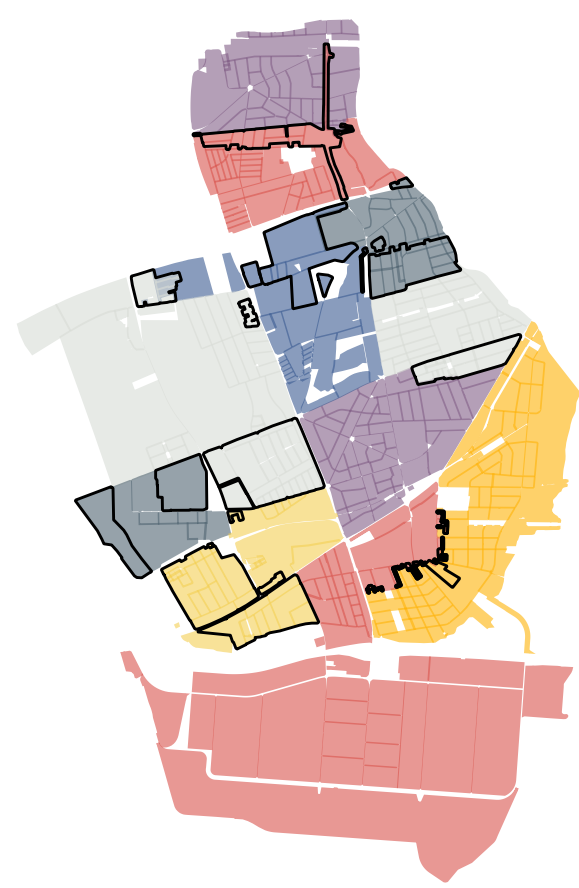

(b) Attendance zones in 2009

Figure 1: Attendance boundary changes in the municipality of Hvidovre

The figures depict the attendance zones in the municipality of Hvidovre in the autumn of 2008 and 2009. See section 3 for a description of the attendance zone data. Some areas differ from the official documentation. These areas are mostly not populated but some measurement error occurs. In the analysis, we use addresses directly to bypass the mismeasurement of geographical entities. The district polygons are only used to measure distances to boundaries.

Definitions of socioeconomic measures for households and schools As Danish private schools are relatively cheap and public schools are free we do not regard pecuniary resources as an important factor in explaining heterogeneity in enrollment behavior. As education and income are highly correlated we, therefore, expect income and education to essentially reflect the same underlying socioeconomic factors. To capture such underlying socioeconomic factors in a simple scalar measure, we construct a household socioeconomic index (henceforth, SES). For the parents of the children, we record income rank, an employment dummy, and a dummy for long-cycle education. We then perform a principal component analysis and define the SES-index as the rank of the first component. The resulting distribution is therefore uniformly distributed and bounded on the unit-interval. Our SES-index is rising in income, employment, and education as illustrated in Appendix Figure A.1 and we therefore conclude that it captures these factors well. ${ }^{20}$ We measure ethnic background with a dummy for being a

\footnotetext{
${ }^{20}$ Appendix A describes this SES-index in detail
} 
non-Western immigrant, descendant or child of descendants (up to the third generation). ${ }^{21}$

To characterize schools we primarily use the average socioeconomic status (SES) among the children enrolled. We refer to this measure as school-SES. We complement this measure with two additional measures; ethnic composition measured as the share of non-Western immigrants (abbreviated NW), and, school value-added (SVA). As with school-SES, we measure NW-share as the share of all students enrolled in a school for each year. For SVA, however, we make use of official measures calculated by the Danish Ministry of Education available on the ministry website. SVA is computed by the ministry using a random-effects model where the outcome is GPA for final exams of primary school in grade 9 controlling for socioeconomic measures. The SVA measure is thus by construction largely uncorrelated with measures of school-SES. Although this measure might be biased, we use it as it is publicly available and therefore part of the information set of households. We discuss the possibility of omitted variable bias in the measure of value-added in Subsection 5.4. SVA is only calculated for schools with 9th graders and we therefore have smaller samples when we use this measure of schools.

An important factor for the choice of school is the geographical distance (see Abdulkadiroğlu et al. (2020) for an example). We calculate the Euclidean distance between home and schools from the centroid of the geographical polygon, in which a household lives.

Sample selection As we investigate initial primary school enrollment we select all children of age 5, i.e. before school enrollment, for which we observe an associated attendance zone. We measure household characteristics at this age to ensure that these outcomes are not affected by the treatment of receiving an unexpected school affiliation. By the same logic, schoolSES and ethnic composition of schools are measured in the year the child turns age 5. In other words, the school characteristics of the original school and the new school to which children are possibly transferred are measured in the year before a boundary change, and are thus exogenous to enrollment decisions of households in our sample. We measure enrollment outcomes at age 7 where we condition on observing these outcomes. In section 5.4 we also exploit a sample of younger children to investigate delayed responses. ${ }^{22}$

For all residential locations in our data, we record changes in formal school affiliation and the year the change occurs. We restrict our attention to addresses which experience a single change or no change in our data and exclude all reassignments that result from the old school closing down. For each address that experiences a change in affiliation, we calculate the time span in years between the current year and the year of the change. A temporal difference to the attendance boundary change of zero implies that the change occurs between the ages of 6 and 7 of the child. A distance in years of 1 means that the change occurs between the ages of 5 and

\footnotetext{
${ }^{21}$ In order to be a non-Western descendant both parents must be non-Danish. The same goes for children of descendants. Thus, one Western parent is sufficient to be of Western descent.

${ }^{22} \mathrm{We}$ focus on 7-year-old children as this age captures the earliest point in time by which we expect all children to have enrolled in primary school. Note that some parents defer enrollment until their children turn 7 years old.
} 
Table 1: Descriptive statistics for children and schools

\begin{tabular}{lcccc}
\hline & Count & Mean & Median & Std. \\
\hline A. Children & & & & \\
\hline Socioeconomic status [SES] & 578,903 & 0.50 & 0.50 & 0.29 \\
Non-western [NW] & 581,457 & 0.13 & & \\
\hline B. Public schools & & & & \\
\hline Socioeconomic status, average & 9,332 & 0.47 & 0.46 & 0.10 \\
Non-Western, share & 9,332 & 0.09 & 0.05 & 0.13 \\
School Value-added & 3,714 & 0.04 & 0.00 & 0.34 \\
\hline C. Private schools & & & & \\
\hline Socioeconomic status, average & 3,413 & 0.49 & 0.51 & 0.16 \\
Non-Western, share & 3,412 & 0.13 & 0.04 & 0.25 \\
\hline
\end{tabular}

The table presents descriptive statistics at the level of children and schools. The children are measured in year 7 while schools are represented once per year.

6.

We then link these addresses to our sample of children and merge it onto the spatial data for attendance boundaries. We calculate changes in geographical Euclidean distances following a change in boundaries from the place of residence when the child is five years old to the original and the newly assigned school. When a boundary changes, the distance changes differently for each household depending on the place of residence. Therefore, we have more variation in distance changes than in our other school measures, which by construction are the same for all households in the attendance zone in a given year.

Descriptive statistics Descriptive statistics for students and schools are presented in Table 1. Average school-SES is 0.47 with a standard deviation of 0.1 . In the results section, the marginal effects of school-SES can therefore be interpreted as a change of one standard deviation of school-SES divided by 10 . For some public schools, we lack data on the publicly provided value-added measure. Sample sizes, therefore, fall when we employ this measure. Private schools have a slightly higher mean school-SES than public schools. However, private schools also have a larger non-Western share reflecting the presence of Muslim private schools. To further describe this we plot the distributions of non-Western share and school-SES in Figure B. 2 and find stark mass points of 0 and 100 percent immigrant-shares in private schools. While we find a mass point at zero immigrants for public schools it is much smaller and we do not find a noticeable share of public schools with 100 percent immigrants. Correspondingly, the variance of school-SES is larger among private schools than public schools. This illustrates that private schools are heterogeneous and work as possible means for households to self-segregate both among immigrants and natives. 


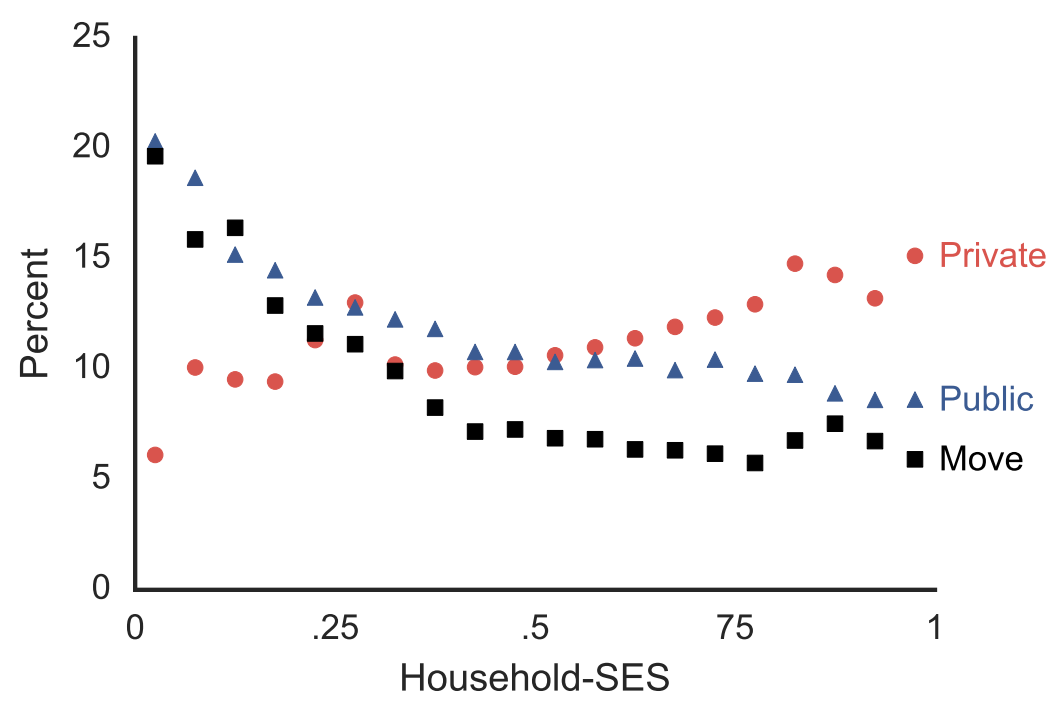

Figure 2: Margins of defiance by household-SES

The figure shows simple means of the three component of Equation (1) within vintiles of household-SES within the cross-sectional sample.

\section{Compliance margins and household sorting}

A Danish household with a child ready to enroll in primary school has several options. The household may simply choose to enroll the child in the district school, thereby complying with the default option. This option is guaranteed by law and therefore always available. We describe this by a binary variable, denoted Comply. When households do not enroll in the district school we group their choices into three mutually exclusive categories: enroll in another public school (Public); enroll in a private school (Private) or move to another attendance zone (Move). Summing gives us the following identity:

$$
\text { Comply }=1-(\text { Public }+ \text { Private }+ \text { Move })
$$

where it is implicit that we regard a move as a single action, regardless of whether the child ends up attending the assigned school in her new location. Each of the elements in Equation (1) corresponds to a dependent variable and we use this identity to decompose responses along the three margins of defiance.

The use of different margins of non-compliance differs along household-SES in the crosssection, as evidenced in Figure 2. Whereas low-SES households tend to send their children to other public schools or to move, private school is the preferred outside option among high-SES households. As low-SES households have higher aggregate rates of defiance in the crosssection than high-SES households, the former might be expected to be more likely to defy reassignment policies than the latter. However, this interpretation overlooks residential sorting 
as a potentially important factor in explaining non-compliance. If high-SES households are able to locate within attendance zones of more desirable schools, they will have less incentive to opt out of the assignment. As such, an initial residential location decision may serve as a substitute to the other margins presented in Figure $2 .^{23}$

To investigate whether residential location decisions serve as a substitute to private school and other public schools we construct graphs in the spirit of the Boundary Discontinuity Design originally introduced by Black (1999). We follow Bayer et al. (2007) and compare households in two adjacent school attendance zones, where we define the "left" school as the school with lower school-SES and vice versa for the "right" school. ${ }^{24}$ The left panel of Figure 3 depicts the mean household-SES as a function of distance to the boundary and shows a clear discontinuity in household-SES at the boundary, which confirms the sorting pattern in Bayer et al. (2007). The average difference in household-SES between two zones is 9 points, roughly equivalent to one standard deviation of school-SES. If boundaries were drawn at random this would be a clear indication that high-SES schools attract high-SES households. However, if households differ in their preference for schools, a high-SES household choosing to live on the left side may differ from a high-SES household on the right side of the boundary in terms of preference for school composition. In other words, if households have made different housing decisions, one cannot expect them to act in the same way following a school reassignment. Additionally, if high-SES households send their children to the local school the discontinuity at the boundary may reflect initial residential segregation and sorting on unobserved amenities.

Unlike Bayer et al. (2007), we have access to data on enrollment for households and can therefore investigate the differences in enrollment decisions around the boundary. Given that higher-SES households on average enroll their children in private schools at a higher rate, we would expect private school enrollment to be higher in the area where more high-SES households locate. We examine this by plotting the share of children enrolled in private school as a function of distance to the boundary in the right panel of Figure 3. However, we find the opposite pattern as evidenced by the discontinuous drop of three points in private school enrollment at the boundary. In other words, even though high-SES households disproportionately relocate to the right side of the boundary, we observe lower private school enrollment. This provides evidence that relocating to high-SES districts serves as a substitute to private school and that school quality, school choice and residential location decisions are intertwined. We provide

\footnotetext{
${ }^{23}$ Importantly, in absence of boundary changes, locating within an attendance zone guarantees enrollment in the associated school. Locating within the attendance zone of a desirable school may, therefore, be a less risky choice than getting on the waiting list of a private school or bet on admission to another public school. This location decision is presumably what drives the positive effects of measures of school quality on house prices found across institutional settings.

${ }^{24} \mathrm{We}$ construct bins of distances such that the addresses located in the lower-SES school attendance zone have negative distances to the boundary and addresses in the high-SES attendance zone have positive distances. We then regress the outcomes on binned distances and boundary-year fixed effects. By including the boundary-year fixed effects, we compare only within boundary regions in the same year. We center our results on the left side, i.e. the side with the lower school-SES.
} 
(a) Mean household-SES

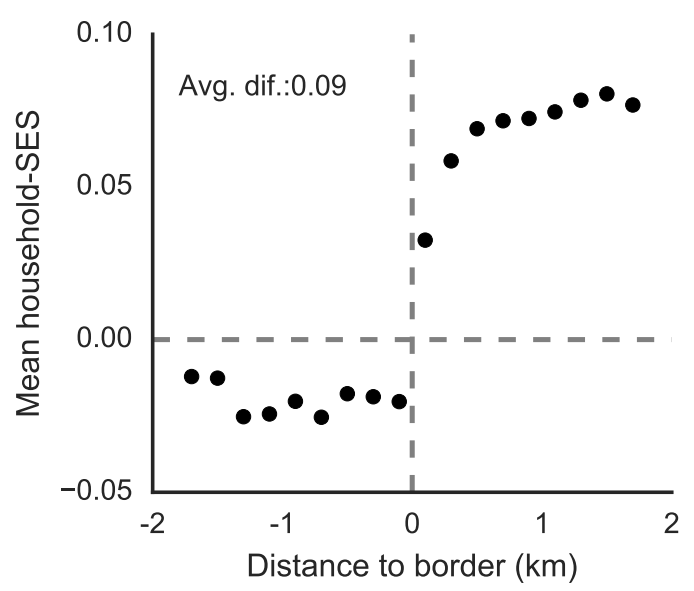

(b) Private school enrollment

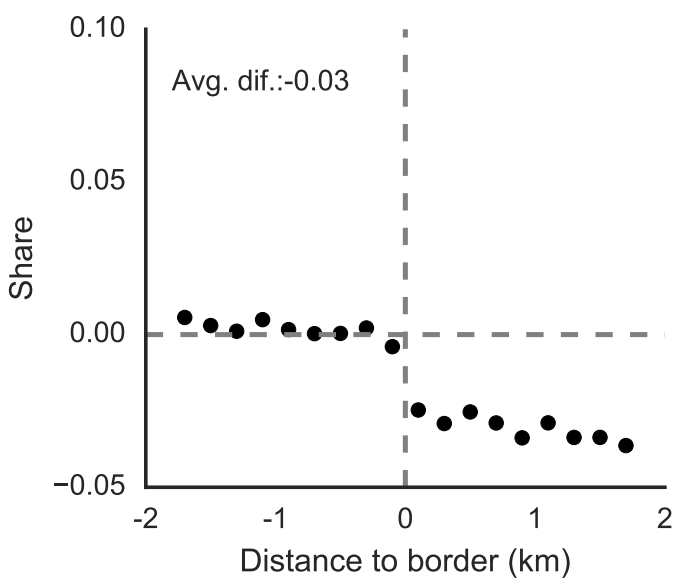

Figure 3: Differences at boundaries between low- and high-SES schools

The figures depict the boundary discontinuity estimates for household-SES and private school enrollment. The dependent variables are displayed in the figure titles. Negative distance to boundary signifies that the household is situated in the district of the two adjacent districts with the lower value of the school characteristic. The models are estimated with fixed effects at the boundary-year level. Results are centered on the left side of the boundary.

further evidence of sorting and enrollment around the boundary in Appendix B. ${ }^{25}$

Due to the simultaneity between residential segregation and school segregation, the Boundary Discontinuity Design does not provide estimates of the relevant policy-counterfactuals of changing school affiliations. If Figure 3 a would be interpreted as balancing tests, the Boundary Discontinuity Design would clearly not be valid. Rather than providing estimates of the causal effects of school characteristics on enrollment choice, the discontinuities in Figure 3 show that residential sorting is inherently interconnected with school segregation. Estimating responses to desegregation policies without conditioning on initial residential segregation is, therefore, not a viable strategy. In the next section, we, therefore, exploit changes in the geographical shape of attendance zones over time to estimate the causal effects of this exact policy while allowing us to condition on household sorting. In Section 5.4 we develop a combination of the Boundary Discontinuity Design and our main difference-in-difference approach to investigate heterogeneity in responses as a function of distance to the boundary.

\section{Behavioral responses to changes in boundaries}

To obtain causal estimates of behavioral responses to reassignment policies, we exploit the changes to attendance boundaries that occur regularly in Danish municipalities. Unaware of

\footnotetext{
${ }^{25}$ For instance, we show that the magnitude of non-compliance differences at boundaries increases with difference school-SES and is evident for all margins in Equation (1) see Figure ??. In addition, to address the unbalanced SES across boundaries we also examine heterogeneity by household-SES in Figure B.3 which shows larger differences at boundaries across all margins for high-SES households.
} 
future changes, two households can relocate to the same attendance zone but end up allocated to two different schools. If the timing of the changes in boundaries is sufficiently random, as we argue below, we can attribute changes in differences in behavior over time to changes in school affiliation. In other words, the boundary changes allow us to estimate the behavioral effects in a difference-in-difference design.

We begin by examining what characterizes the areas where policies of redrawing boundaries were enacted. Figure 4a shows that children who experience redrawing of boundaries tend to be located in more densely populated areas with a median of 1,600 thousand people pr. square kilometer compared to 900 people pr. square kilometer among the population at large. Accordingly, children living in municipalities with larger population densities are also more likely to experience a boundary change but with large variation, as evidenced by Figure $4 \mathrm{~b}$ where municipalities are plotted according to density and share of the sample that is treated. The population-weighted correlation between treatment propensity (i.e. experiencing a boundary change) and mean population density is 0.26 . While denser municipalities are more likely to enact boundary changes, the low correlation implies that boundary changes are not solely an urban phenomenon and occur in most regions of the country. Conditional on treatment, the intensity of changes in school characteristics due to boundary changes is somewhat increasing in urban density, though not uniformly so as seen in Figure 4c. Large changes also occur outside highly urbanized areas and we, therefore, conclude that the variation we are exploiting is fairly representative of the population in general though weighted toward urban and suburban areas. ${ }^{26}$ Lastly, Figure $4 \mathrm{~d}$ shows the distribution of treatment propensity at the district level using our sample definitions. Most boundary changes are small, affecting on average 16 percent of an incoming cohort. Thus, while larger changes do occur, most changes only affect a minority of children in a given district.

To complement the results in Figure 4 we estimate models of the propensity to change boundaries from characteristics of the area and present the results in Appendix Table B.1. Again, we find that dense municipalities change school boundaries at a higher rate, see column (1). At the level attendance boundaries, we find that both the mean and variation in population density within a district as well as its student diversity in SES are relevant predictors of changes in boundaries, see column (2).

\subsection{Identification and estimation}

We estimate household responses to changes in school affiliation in a difference-in-difference framework. We use two approaches. The first approach is an event-study design and estimates

\footnotetext{
${ }^{26}$ Large changes in value-added seem to occur at places with little support in the distribution. As previously mentioned, we suspect omitted variable bias in this value-added measure though we note that the public valueadded measure does not correlate much with school-SES and school non-Western share and thus variation in changes to value-added comes from a different part of the distribution than school-SES and non-Western share.
} 


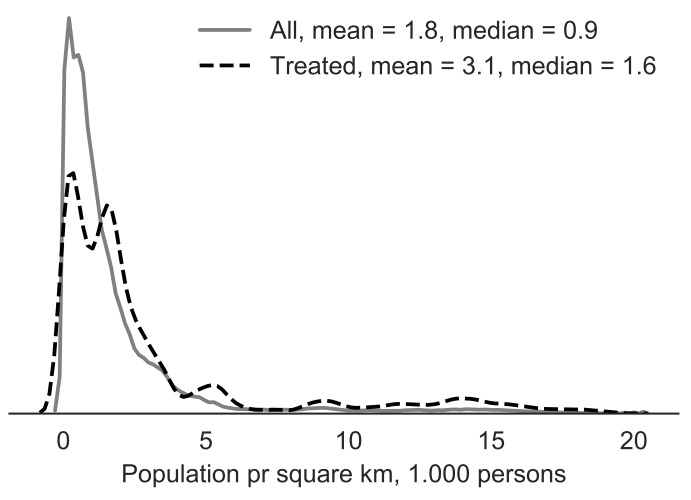

(a) Treatment status by dens., individual

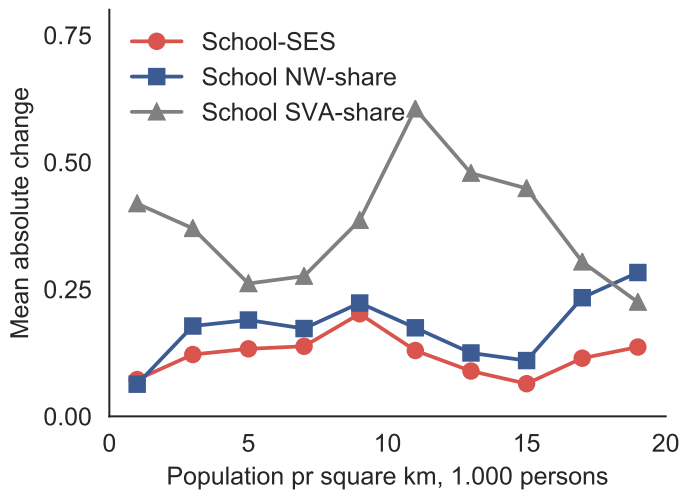

(c) Treatment intensity by dens., individual

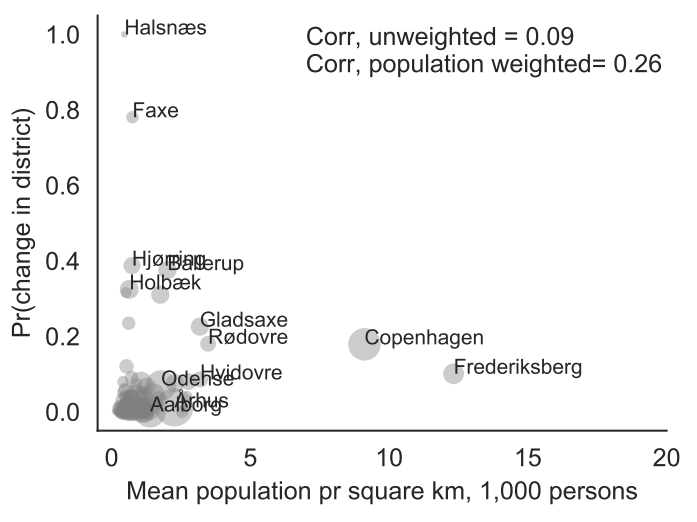

(b) Treatment status by dens., municipal

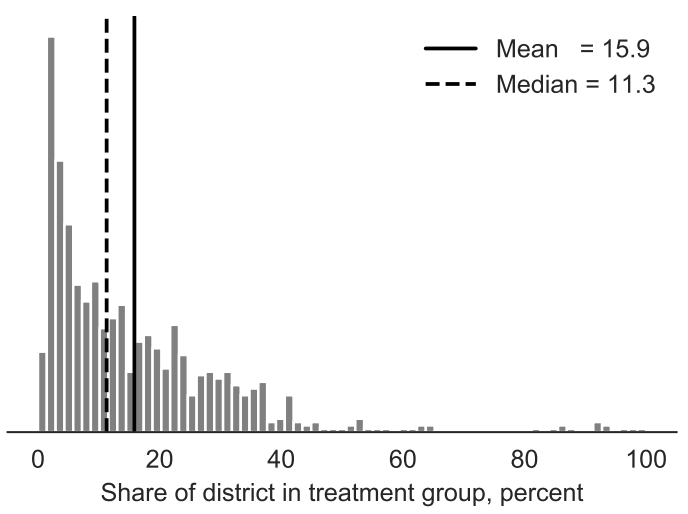

(d) Share in district treated

Figure 4: Population density and boundary changes

Figure 4a shows the distribution of individually calculated population densities for all children and for treated children. These densities are calculated for each spatial polygon in our data. Figure $4 \mathrm{~b}$ depicts the link between mean municipal density on the $\mathrm{x}$-axis and the share experiencing a change in school affiliation. The size of the points signifies the number of observations in each municipality. Figure $4 \mathrm{c}$ shows the mean absolute change in school characteristics among treated by population density. Figure $4 \mathrm{~d}$ shows the distribution of treatment shares within districts excluding districts where none or all in the incoming cohort are transferred.

responses to positive and negative treatment variables for each of the years before and after the boundary changes. This approach is flexible and allows us to gauge pre-trend. The second approach pools the years immediately before the change and the years immediately after to compute marginal effects of changes to school characteristics.

\section{Modeling response to positive and negative treatment}

We begin the difference-in-difference analysis by investigating the responses over time. To capture the effect from characteristic changes separate from the "pure" effect from a surprise change we construct a treatment indicator for all addresses, which are shifted. We categorize the changes in school SES resulting from boundary changes into three treatment groups: positive, with higher school-SES in the new district school compared with the old; negative, which have lower school-SES; and, "negligible" change. The latter category is taken as reference and 
defined as when the change in average SES is numerically smaller than 0.1 which represents a standard deviation of the school level SES distribution. ${ }^{27}$

Let $t_{a}$ be the year in which boundary $a$ is changed. We focus on the three following indicator variables, which correspond to our three treatment categories: $T_{a}$ if treated, $T_{a}^{+}$for positive treatment, and $T_{a}^{-}$for negative treatment. We center our estimates in the year before the change of boundaries. We are interested in comparing addresses that were both within the same year and within the same attendance boundary prior to the change. We implement this comparison by including a fixed effect for the original attendance boundary $s$ at time $t .{ }^{28}$ As we only compare addresses within the same original attendance zone and therefore the same municipality, we ensure equal levels of taxation and overall school funding. ${ }^{29}$ We estimate a linear probability model of the following form with Ordinary Least Squares (OLS):

$$
\begin{aligned}
Y_{\text {iast }} & =\alpha_{T} T_{a}+\alpha_{-} T_{a}^{-}+\alpha_{+} T_{a}^{+} \\
& +\sum_{\tau=-4, \tau \neq-1}^{4}\left[\left(\beta_{T}^{\tau} T_{a}+\beta_{-}^{\tau} T_{a}^{-}+\beta_{+}^{\tau} T_{a}^{+}\right) \cdot \mathbf{1}\left(t_{a}=\tau\right)\right]+\mu_{s t}+\varepsilon_{i a s t},
\end{aligned}
$$

where $Y_{i t s}$ is the outcome of interest for child $i$ aged 7 at time $t$ living at address $a$ at the age of 5 in original attendance zone, $s$. The effect on enrollment of changes to school-SES are captured the coefficients on the interactions, $\beta_{T}^{\tau}, \beta_{-}^{\tau}$; and, $\beta_{+}^{\tau} .{ }^{30}$

Our model identifies households' responses to changes in schooling under certain assumptions. A sufficient requirement is that treatment assignment within the old SAB and subsequent relocation are independent of household characteristics. We verify that observable characteristics are not related to treatment and do not change systematically over time, see Subsection 5.4. While we check for sorting on observable characteristics, there may still be unobserved sorting. For instance, households in the middle of a SAB for a high-SES school may have stronger preferences for socioeconomic composition in a school. However, the difference-in-differences method allows us to verify this is not an issue by examining the pre-trends captured by coefficients for $\tau<0$, i.e. prior to the change.

We emphasize that our approach does not identify preferences. The reason is that the available choice set is unobserved and may differ across households. Rather than estimating preferences, we estimate the response of households exposes to boundary changes. These responses

\footnotetext{
${ }^{27}$ Although we have multiple measures of school characteristics, we focus only on school-SES in this subsection. In Appendix B we repeat this analysis using share with non-Western heritage and school value-added, see Figure B.6.

${ }^{28}$ For treated parcels, we assign the zone prior to the change, regardless of the value of $t$.

${ }^{29}$ Note that our difference-in-difference model is more flexible than the boundary discontinuity design estimates presented earlier as we do not condition on the boundary but on the attendance zone, i.e. either side of the boundary.

${ }^{30}$ The specification in Equation (2) implies that $\beta_{-}^{\tau}$ and $\beta_{+}^{\tau}$ are interaction terms describing the intensity of treatment. In other words, the parameters describe how the mean effect on household behavior of a change in attendance boundaries is affected by the change in school characteristics.
} 
are the immediate policy-relevant responses, though a product of both demand (preferences) and supply (methods to opt-out).

\section{Modeling marginal responses}

To measure how households respond to boundary changes we decompose the compliance rate into the possible margins of response. We simplify the estimation by collapsing the time dimension and employ a two-period difference-in-difference model with continuous treatment where we only exploit variation in the years immediately before and after the boundary change.

Let $\Delta Q_{s s^{\prime}}=Q_{s^{\prime}}-Q_{s}$ be the change in school characteristic when reassigned from schools $s$ to $s^{\prime}$. We record $\Delta Q_{s s^{\prime}}$ in the year before address $a$ is transferred to the attendance zone of school $s^{\prime}$. We estimate models of the following form:

$$
Y_{\text {iass't }}=\alpha_{0} T_{a}+\beta_{0} \Delta Q_{s s^{\prime}}+\alpha_{1} T_{a} \times \text { Post }_{a t}+\beta_{1} \Delta Q_{s s^{\prime}} \times \text { Post }_{a t}+\mu_{s t}+\varepsilon_{i a s s^{\prime} t},
$$

where a change in characteristic, $\Delta Q_{s s^{\prime}}$, equals zero for those addresses which do not experience a change (that is $s=s^{\prime}$ ). Our central parameter, $\beta_{1}$, is therefore once again interpreted as an interaction term. This approach yields a number of advantages. First, by including the changes as a continuous measure in the regression we obtain estimates of marginal effects, which can be used for prediction. Second, we can control for other changes in regard to school assignments occurring simultaneously, most notably changes in distance to the district school. Finally, we can include multiple school characteristics simultaneously in the model, though we will discuss the somewhat subtle changes in interpretation when multiple measures are included.

Our results should be interpreted as the immediate policy effect of boundary changes on school enrollment. Further, the results should be interpreted as the first-order responses of those who get reassigned due to boundary changes. In other words, we are not accounting for factors such as social multipliers where changes in school-SES induce yet more parents to opt into the local public school. Such estimates would require us to estimate the peer effect and model the location decision and preferences of all households in the economy. As we document systematic defiance and we would expect heterogeneous effects of schools (and peers) on outcomes, we do not deem research designs using assignments as instruments to estimate peer effects or school effects as credible in a context where defiance breaks the monotonicity link between instruments and treatment. Further, as mentioned, the opaque manner in which school choice is estimated does not allow us to identify preferences directly, as we do not observe the actual options that households have, i.e. access to other public and private schools. We, therefore, abstain from estimating the parameters which are necessary to evaluate full equilibrium effects in models such as those proposed by Epple et al. (2004) and Nechyba (2000). This will also be reflected in our policy simulations in the end of the paper. 


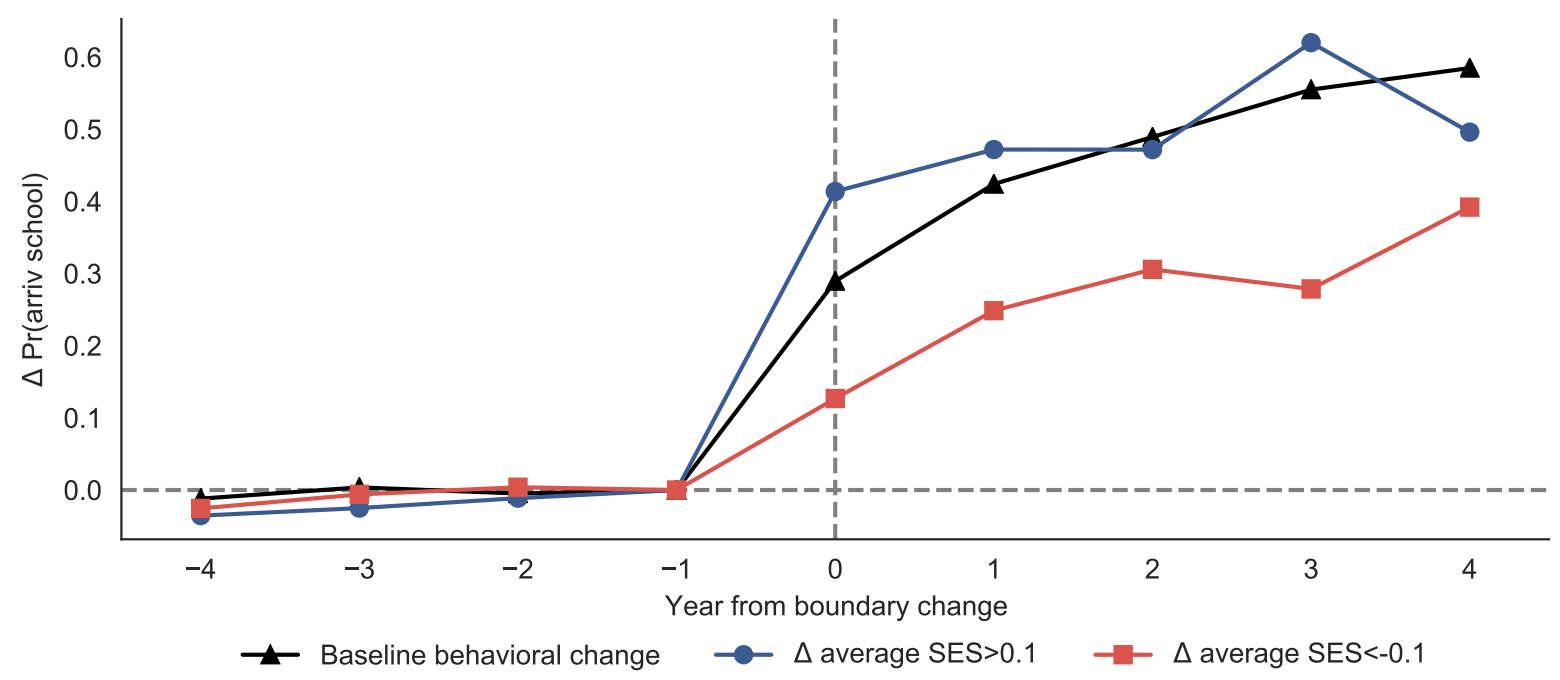

(a) Change in probability or enrolling in new school

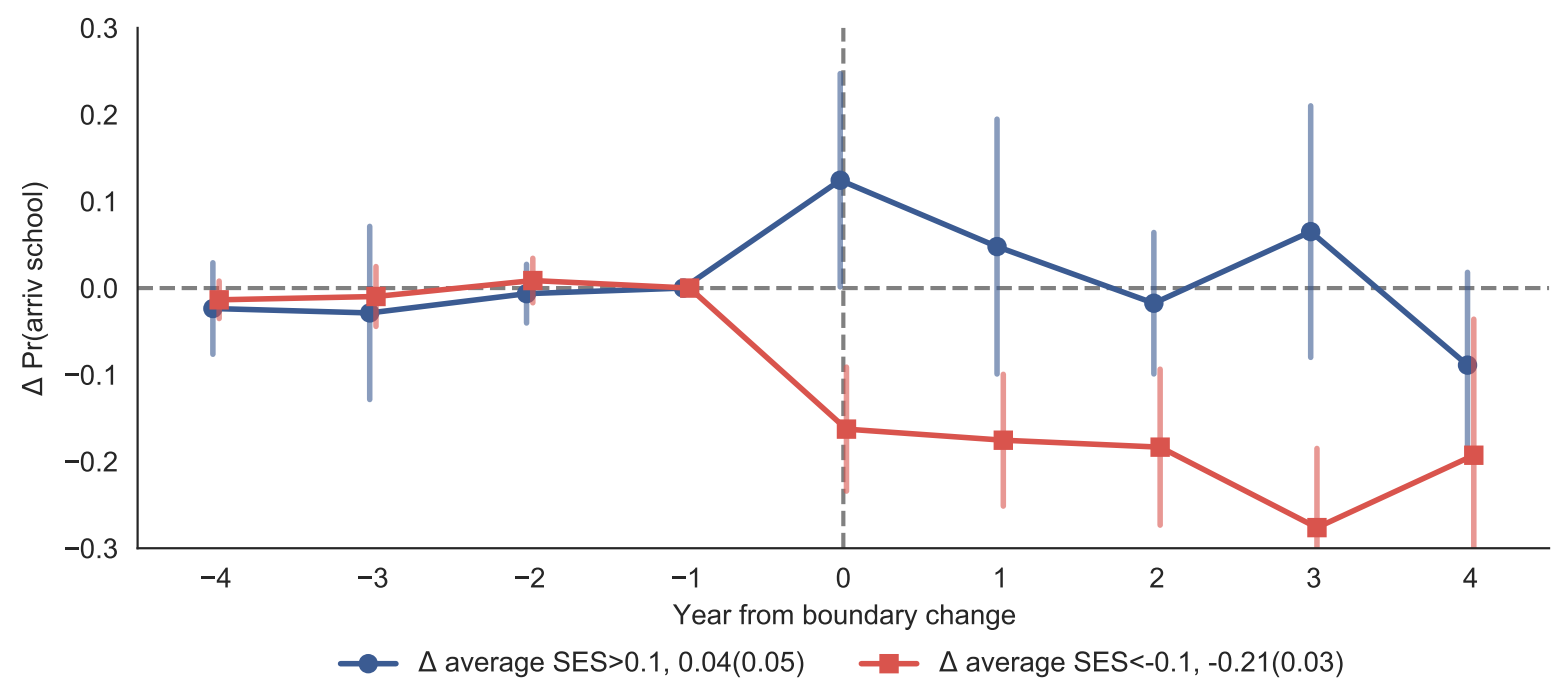

(b) Deviation from baseline change in probability of enrolling in new school

Figure 5: Compliance response to a change in SAB by school characteristic change

Figure 5a display changes in estimated compliance rates based on the model in (2). The black lines depict estimated coefficients of $\beta_{T}^{\tau}$, while the blue and red line depicts coefficients of $\beta_{T}^{\tau}+\beta_{-}^{\tau}$ and $\beta_{T}^{\tau}+\beta_{+}^{\tau}$ respectively. Figure $5 \mathrm{~b}$ displays the interaction terms, $\beta_{-}^{\tau}$ and $\beta_{+}^{\tau}$, along with 95-percent confidence intervals. The parameters represent the difference in the likelihood of enrolling in the new district school, when the average SES at a school level changes, relative to the average arrival probability following a district change. The dependent variable is binary and equals one if the child is enrolled in the district school at age 7 based on the district at age 7 for the address at age 5. The y-axis denotes the excess probability of enrolling relative to baseline. The model is estimated with "origin-attendance-zone"-year fixed effects. Standard errors are clustered on the 'origin-attendance-zone"level. Results are centered at the year before the boundary change. Estimates from a simple before-after-DID are reported in the legends of Figure $5 b$. 


\subsection{Estimating responses to positive and negative shocks}

We begin by estimating model (2) where the outcome is enrollment in the newly assigned school after a change in the attendance boundary. ${ }^{31}$ We plot the estimates in Figure 5a where the black line depicts the baseline change in the probability of enrolling in the new school as a function of time from the boundary change. The black line, therefore, depicts the change in enrollment response of households when there is no differences in school-SES between the old and the new school compared to the change in the enrollment probability of the households from the same original attendance zone who were not transferred. If redrawing attendance boundaries is an effective instrument, the probability of enrolling in a newly assigned school should rise discontinuously at the time of change. This is clearly the case. The probability of enrolling increases by almost 30 percentage points the first year and continues to rise to around 50 percentage points, which is well within the range of common enrollment rates.

The red and blue lines in Figure 5a depict the enrollment propensity when the change in average SES is numerically larger than a standard deviation of the school-level SES distribution. If households experience a positive change in school-level SES of more than a standard deviation (the blue line), the compliance rate rises by around 10 percentage points in the first year which, however, is insignificant as seen in Figure 5b. Four years after the change, the compliance rate converges to the baseline, which is most likely due to the sorting over time as incoming families with children know the new school association in later years. However, if the average school-SES falls by a standard deviation (the red line), the average compliance over the years is 21 percentage points lower than the average enrollment rate and does not seem to converge over time. This implies that there are lasting falls in compliance for areas where the newly assigned school has a weaker socioeconomic composition.

The completely flat pre-trends in Figure $5 b$ provide support of the necessary assumptions for a causal interpretation of the relationship between school characteristics and compliance with the school assignment mechanism as we outline in Subsection 5.1. Moreover, we further investigate threats to identification from changes in composition as well as definitions of outcome variables in Subsection 5.4.

\subsection{Estimating marginal responses}

After having established how SAB changes affect the enrollment of children we move on to estimate the marginal effects captured by the models specified in (3). To limit the role of composition changes, we limit our data to include only observations two years prior and two years after a boundary change. We begin by estimating Equation (3) for overall compliance with

\footnotetext{
${ }^{31}$ For the non-shifted addresses within a SAB, we assign arrival school as the arrival school of those that are shifted. A few SABs experience exchanges between multiple other SABs. In these cases, we assign the closest possible arrival school to the non-shifted addresses.
} 
Table 2: Compliance as a function of SAB change

\begin{tabular}{|c|c|c|c|c|c|}
\hline & (1) & (2) & (3) & (4) & (5) \\
\hline $\mathrm{T} \times$ Post & $\begin{array}{l}0.32 \\
(0.01)\end{array}$ & $\begin{array}{c}0.33 \\
(0.01)\end{array}$ & $\begin{array}{c}0.33 \\
(0.01)\end{array}$ & $\begin{array}{c}0.29 \\
(0.01)\end{array}$ & $\begin{array}{c}0.30 \\
(0.01)\end{array}$ \\
\hline$\Delta$ Dist $\times$ Post & $\begin{array}{l}-0.05 \\
(0.00)\end{array}$ & $\begin{array}{l}-0.05 \\
(0.00)\end{array}$ & $\begin{array}{c}-0.05 \\
(0.00)\end{array}$ & $\begin{array}{c}-0.08 \\
(0.01)\end{array}$ & $\begin{array}{l}-0.07 \\
(0.01)\end{array}$ \\
\hline$\Delta \mathrm{SES} \times$ Post & & $\begin{array}{c}0.72 \\
(0.04)\end{array}$ & & & $\begin{array}{c}0.54 \\
(0.08)\end{array}$ \\
\hline$\Delta \mathrm{NW} \times$ Post & & & $\begin{array}{c}-0.41 \\
(0.03)\end{array}$ & & $\begin{array}{c}-0.22 \\
(0.06)\end{array}$ \\
\hline$\Delta \mathrm{SVA} \times$ Post & & & & $\begin{array}{c}0.07 \\
(0.01) \\
\end{array}$ & $\begin{array}{c}0.11 \\
(0.01)\end{array}$ \\
\hline $\mathrm{N}$ & 48,517 & 48,517 & 48,517 & 47,095 & 47,095 \\
\hline
\end{tabular}

Column 1 contains a regression model with compliance as the dependent variable where none of the school characteristics are included, only change in distance from to designated school. Columns 2-4 display regression results for the model presented in Equation (3) for one school characteristic at a time. Column 5 displays the result of an estimation using all characteristics at a time. The models are estimated with "origin-attendance-zone"-year fixed effects. Standard errors are in parentheses and clustered on the municipality level. Full output can be found in Appendix Table B.2.

one school characteristic at a time. The first partial model, which includes only the baseline response and reaction to change in distance is shown in column 1 in Table 2 . The estimate shows that enrollment into the newly assigned school on average increases by around 32 percentage points among those who are actually reassigned, as seen by the value of the parameter on $T \times$ Post. The coefficient on distance is negative and statistically significant. This implies that the further a child must travel to the district school the lower the compliance. This is intuitive as travel time is associated with a decrease in utility of households. The coefficient on distance remains negative and statistically significant in all our models.

In the models with only a single school characteristic the coefficients on the interaction terms on SES and NW-share are highly significant, see columns 2-3 in Table 2. A standard deviation increase of average school-SES entails an increase in compliance of around $(0.72 \times 0.1) \times 100 \approx 7.2$ percentage points, which corresponds to roughly 20 percent of the baseline first-year increase in enrollment of 33 percentage points. Conversely, an increase of ten percentage points in the NW-share decreases the compliance by 4.1 percentage points. The school value-added has a positive coefficient, indicating a positive effect on compliance. Our value-added measure has a standard deviation of 0.35 so the estimate on value-added of 0.07 implies that an increase of a standard deviation change in value-added leads to an increase in compliance of 2.3 percentage points, which is a substantially smaller response than the one estimated for school-SES. ${ }^{32}$

Column 5 of Table 2 includes all school characteristics in a single regression. While the co-

\footnotetext{
${ }^{32}$ The coefficient on distance increases in magnitude from -0.05 to -0.08 when SVA is included, due to a large correlation between the SVA and distance. This is most likely due to population density being an omitted variable in the model for measuring SVA.
} 
efficient on value-added changes little, we see substantial changes in the parameters on schoolSES and NW-share. These changes in coefficients are due to a large, negative correlation of -0.87 between changes in school-SES and changes in the NW-share. This correlation makes it extremely difficult to separate out partial effects of changes in socioeconomic and ethnic composition. A subtle issue is whether households can make this distinction themselves. It may be the case, that parents simply use the share with Non-Western heritage as a proxy for school-SES. As described earlier, we constructed our SES-index from a principal component analysis. This is likely not a perfect measure of SES. If we are willing to assume the NW-share is really just another proxy for (unobserved) socioeconomic composition, we can employ an insight developed by Lubotsky and Wittenberg (2006) and combine the two estimates to yield a coefficient on a "true" SES-index. If we assume that $\Delta N W$ correlates negatively with the unobserved index, then the combined parameter is given by $0.54-1 \times(-0.22)=0.76$, which is almost equal to the parameter value of 0.72 on SES in column 2 of Table $2 .{ }^{33}$ This back-of-theenvelope calculation leads us to conclude that the NW-share and our constructed school-SES may essentially measure the same underlying socio-economic conditions and cannot meaningfully be separated in our data. ${ }^{34} \mathrm{We}$, therefore, proceed to focus mainly on the SES-index and abstain from estimating regressions with more than one school characteristic at a time.

Margins of response We have previously defined how households may defy the assignment mechanisms through different choice margins. Because we investigate unexpected changes to boundaries, we suspect that an important margin is to enroll in the school of the original attendance zone. We, therefore, expand the public school margin, such that the original district school is measured separately and Equation (1) is modified to encompass four means of noncompliance:

$$
\text { Comply }=1-\text { Original }- \text { Public }- \text { Private }- \text { Move, }
$$

where Comply takes the value of one if the child enrolls in the assigned district school, Original denotes the departure school and Public now denotes a public school different from original school and the newly assigned school. Private denotes private school enrollment and if the family moved out of the district between ages 5 and 7 of the child, Move takes the value of one. We decompose the non-compliance rate by estimating models corresponding to column 2

\footnotetext{
${ }^{33}$ Formally, simplifying notation, we assume that the true SES, $S E S^{*}$, is approximated by our index, $S E S$, and the Non-Western share, $N W: y=\beta S E S^{*}+\varepsilon$ where we have that $S E S^{*}=S E S+u_{1}$ and $S E S^{*}=-\rho N W+u_{2}$. We set the coefficient on SES to one and therefore set the scale of the true SES. Then Lubotsky and Wittenberg (2006) show that $\beta$ may be approximated by simultaneously regressing $y$ on $S E S$ and $N W$ and adding up the coefficients according to their covariances as $\beta=\beta_{S E S}+\frac{\operatorname{cov}(y, N W)}{\operatorname{cov}(y, S E S)} \beta_{N W}$. With covariance, $\operatorname{cov}(y, S E S)=0.00546$ and $\operatorname{cov}(y, N W)=-0.00549$ we obtain the values in the main text.

${ }^{34}$ This is naturally a product of the Danish context. The correlations may differ between countries and over time. In the present case, we think of the correlation as being policy-invariant, though this may not be true in the long term.
} 
Table 3: Responses along margins

\begin{tabular}{|c|c|c|c|c|c|}
\hline & Comply & Original & Public & Private & Move \\
\hline & \multicolumn{5}{|c|}{ - a) Constant homogeneous responses - } \\
\hline \multirow[t]{2}{*}{$\mathrm{T} \times$ Post } & 0.33 & -0.12 & -0.18 & -0.03 & 0.01 \\
\hline & $(0.01)$ & $(0.02)$ & $(0.01)$ & $(0.01)$ & $(0.01)$ \\
\hline \multirow{2}{*}{$\Delta$ Dist $\times$ Post } & -0.05 & 0.01 & 0.05 & -0.02 & 0.01 \\
\hline & $(0.00)$ & $(0.02)$ & $(0.01)$ & $(0.01)$ & $(0.01)$ \\
\hline \multirow[t]{2}{*}{$\Delta \mathrm{SES} \times$ Post } & 0.72 & 0.38 & -0.79 & -0.21 & -0.10 \\
\hline & $(0.04)$ & $(0.12)$ & $(0.08)$ & $(0.09)$ & $(0.09)$ \\
\hline \multirow[t]{2}{*}{$\mathrm{N}$} & 48,517 & 48,517 & 48,517 & 48,517 & 48,517 \\
\hline & -b) Pos & ve and neg & tive chan & s in scho & $-S E S-$ \\
\hline \multirow[t]{2}{*}{$\mathrm{T} \times$ Post } & 0.36 & -0.11 & -0.21 & -0.03 & -0.00 \\
\hline & $(0.01)$ & $(0.03)$ & $(0.02)$ & $(0.02)$ & $(0.02)$ \\
\hline \multirow[t]{2}{*}{$\Delta$ Dist $\times$ Post } & -0.05 & 0.00 & 0.05 & -0.02 & 0.01 \\
\hline & $(0.00)$ & $(0.02)$ & $(0.01)$ & $(0.01)$ & $(0.01)$ \\
\hline \multirow[t]{2}{*}{$\Delta^{+} \mathrm{SES} \times$ Post } & 0.46 & 0.33 & -0.58 & -0.17 & -0.05 \\
\hline & $(0.08)$ & $(0.24)$ & $(0.15)$ & $(0.17)$ & $(0.17)$ \\
\hline \multirow[t]{2}{*}{$\Delta^{-}$SES $\times$Post } & 0.95 & 0.46 & -1.00 & -0.25 & -0.17 \\
\hline & $(0.07)$ & $(0.24)$ & $(0.15)$ & $(0.17)$ & $(0.17)$ \\
\hline \multirow[t]{2}{*}{$\mathrm{N}$} & 48,517 & 48,517 & 48,517 & 48,517 & 48,517 \\
\hline & \multicolumn{5}{|c|}{ - c) Household heterogeneity in responses - } \\
\hline \multirow[t]{2}{*}{$\mathrm{T} \times$ Post } & 0.33 & -0.13 & -0.17 & -0.02 & -0.00 \\
\hline & $(0.01)$ & $(0.03)$ & $(0.02)$ & $(0.02)$ & $(0.02)$ \\
\hline \multirow[t]{2}{*}{$\mathrm{T} \times$ Post $\times \mathrm{SE} \mathrm{Q} 2$} & 0.03 & 0.00 & -0.01 & -0.04 & 0.01 \\
\hline & $(0.01)$ & $(0.04)$ & $(0.03)$ & $(0.03)$ & $(0.03)$ \\
\hline \multirow[t]{2}{*}{$\mathrm{T} \times$ Post $\times \mathrm{SE} \mathrm{Q} 3$} & -0.01 & -0.00 & -0.02 & 0.01 & 0.02 \\
\hline & $(0.01)$ & $(0.04)$ & $(0.03)$ & $(0.03)$ & $(0.03)$ \\
\hline \multirow[t]{2}{*}{$\mathrm{T} \times$ Post $\times \mathrm{SE} \mathrm{Q} 4$} & 0.01 & 0.01 & -0.02 & -0.01 & 0.01 \\
\hline & $(0.01)$ & $(0.04)$ & $(0.02)$ & $(0.03)$ & $(0.03)$ \\
\hline \multirow[t]{2}{*}{$\Delta$ Dist $\times$ Post } & -0.06 & 0.06 & 0.05 & -0.04 & -0.00 \\
\hline & $(0.01)$ & $(0.03)$ & $(0.02)$ & $(0.02)$ & $(0.02)$ \\
\hline \multirow[t]{2}{*}{$\Delta$ Dist $\times$ Post $\times$ SE Q2 } & 0.04 & -0.07 & 0.00 & 0.00 & 0.02 \\
\hline & $(0.01)$ & $(0.04)$ & $(0.02)$ & $(0.03)$ & $(0.03)$ \\
\hline \multirow[t]{2}{*}{$\Delta$ Dist $\times$ Post $\times$ SE Q3 } & 0.01 & -0.07 & 0.01 & 0.03 & 0.01 \\
\hline & $(0.01)$ & $(0.03)$ & $(0.02)$ & $(0.03)$ & $(0.02)$ \\
\hline \multirow[t]{2}{*}{$\Delta$ Dist $\times$ Post $\times$ SE Q 4} & -0.01 & -0.05 & -0.01 & 0.06 & 0.00 \\
\hline & $(0.01)$ & $(0.04)$ & $(0.02)$ & $(0.03)$ & $(0.03)$ \\
\hline \multirow[t]{2}{*}{$\Delta \mathrm{SES} \times$ Post } & 0.43 & 0.63 & -0.77 & -0.17 & -0.13 \\
\hline & $(0.07)$ & $(0.22)$ & $(0.13)$ & $(0.16)$ & $(0.15)$ \\
\hline \multirow[t]{2}{*}{$\Delta \mathrm{SES} \times$ Post $\times \mathrm{SE}$ Q 2} & 0.40 & -0.56 & 0.09 & 0.13 & -0.05 \\
\hline & $(0.10)$ & $(0.32)$ & $(0.19)$ & $(0.23)$ & $(0.23)$ \\
\hline \multirow[t]{2}{*}{$\Delta \mathrm{SES} \times$ Post $\times \mathrm{SE} \mathrm{Q} 3$} & 0.24 & -0.22 & -0.26 & 0.03 & 0.20 \\
\hline & $(0.11)$ & $(0.33)$ & $(0.21)$ & $(0.24)$ & $(0.24)$ \\
\hline \multirow[t]{2}{*}{$\Delta \mathrm{SES} \times$ Post $\times$ SE Q4 } & 0.52 & -0.29 & 0.00 & -0.23 & 0.00 \\
\hline & $(0.09)$ & $(0.29)$ & $(0.18)$ & $(0.21)$ & $(0.21)$ \\
\hline $\mathrm{N}$ & 48,294 & 48,294 & 48,294 & 48,294 & 48,294 \\
\hline
\end{tabular}

Columns display regression results for the model presented in Equation (3) using SES as a measure of schools with margins of response displayed in the columns title. The top panel contains models estimated with homogeneous compliance both in the sign of change and household-SES. The middle panel contains models with positive and negative shocks while the lower panel shows heterogeneity in responses for household-SES quartiles where the first quartile is the baseline. The models are estimated with "origin-attendance-zone"-year fixed effects. Standard errors are in parentheses and clustered on origin 'origin-attendance-zone"-level. The full output of the top panel can be found in Appendix Table B.3. Remaining output available upon request. 
in Table 2 using each component from equation (4) as a dependent variable.

The results are displayed in panel a) at the top of Table 3. Column Comply reproduces column 2 of Table 2. In accordance with Equation (4) the remaining columns approximately sum to (minus) the first column. This decomposition shows that the changes in compliance primarily stem from the publicly provided option of choosing other public schools, measured by the estimates in the columns Original and Public, see estimated coefficients in panel a) of Table 2. When school-SES increases, the majority of the increase in compliance stems from a diminishing propensity to choose other public schools, as seen by the estimate of -0.79 on SES in the Public column in the top panel of Table 3. An additional source of increased compliance is the decrease in private school enrollment, seen in the Private column. The increase in compliance is, however, attenuated by an increase in the propensity to stay in the original district school. We show below that this response along the Original-margin stems mostly from low-SES households staying behind.

For all five response margins in Equation (4) we estimate event-study models corresponding to Figure 5 and present the results in Appendix Figure B.4. Due to the discretization, the estimates are more imprecise but the figures confirm the general conclusions from Table 3. Appendix Figure B.5 further discretizes treatment and shows that larger changes in school-SES create larger household responses at most margins. ${ }^{35}$

Positive and negative changes in school-SES We previously found that the response to boundary changes depends on whether households are transferred to stronger or weaker attendance zones in terms of school-SES. To further elaborate on this heterogeneity we interact our continuous measure of change in school-SES with an indicator for the sign of this change. The estimated coefficients are shown in panel b) in the middle of Table 3. Consistent with the previous findings in Figure 5, we find that the responses are larger for negative shocks. For overall compliance, the responsiveness to school-SES is twice as large when households are faced with a negative change compared to a positive change in school-SES (with parameters of 0.95 and 0.46 respectively). This difference in sensitivity is driven by the Public and Move margins, though the latter estimate is imprecise. This implies that a policy of moving children out of poor schools is more effective than moving children into poor schools.

Household heterogeneity in behavioral responses Preferences and constraints for admission to schools likely differ at the household level. These differences can lead to heterogeneity in responses to changes in SABs. To elicit such differences, we interact the model presented in Equation (3) with the SES quartile of the household. The estimated effects on overall compliance along with different margins of response are shown in panel c) found in the lower part of

\footnotetext{
${ }^{35}$ As evidenced in Appendix Figure B.5d, large changes in school-SES tend to be followed by moving years after the change though not immediately after the boundary change. This would imply composition changes in the difference-in-difference design if we would not limit our sample to within two years of the boundary change.
} 
Table 3. When the schools have equal SES, we find no heterogeneity in household responses as evidenced by the first eight rows. In other words, when the original and new schools are alike, high-SES parents do not respond differently than low-SES parents to reassignment.

Yet, we find a high degree of heterogeneity in responses when the two schools are not alike in terms of school-SES. The sensitivity to school-SES is increasing in household SES, evidenced by the estimates in the three bottom rows of the Comply column. The compounded response from a change in school-SES is around 2.2 times larger for the highest quartile compared to the lowest quartile. ${ }^{36}$ In other words, the higher the socioeconomic status of the household, the larger the expected response to school-SES. The relatively low estimate for households in the first SES quartile is explained by a large tendency to stay behind in the "original" school. If households value higher school-SES, then the assignment to a higher-SES school weakly improves the choice set of those households who would otherwise have sent their child to private school because they by law always have access to the zoned school. Thus one would expect households on the private school margin to be likely to respond positively in terms of compliance to being allocated to a higher-SES school. This intuition is confirmed in the results. Summing up the baseline estimate on the Private margin, -0.17 , with the appropriate household-SES interactions, the aggregate effect of a change in school-SES on the household margin is negative for all household-SES quartiles though all estimates on the private school margins are imprecise. This implies that households who would counter-factually have enrolled their child in private school, to a varying degree, choose to opt into the new school following a prospective increase in school-SES in the local public school. For the highest quartile of household-SES, almost half of the response is driven through the private school margin. We emphasize that the responses we measure are a function of both preferences and constraints. Thus, if access to schools varies between SES-quartiles, the heterogeneity cannot solely be attributed to preferences.

\subsection{Further heterogeneity in responses and robustness}

In this section, we present further results and robustness checks. First, we focus on younger children, as their parents have a longer time span to plan enrollment and thus may be less constrained in their outside options. We then investigate whether responses differ depending on the birth order of the child. We proceed to investigate threats to identification in our difference-in-differences design and whether responses are a function of distance to the border and the implication for generalizing our findings. Lastly, we investigate an alternative measure of value-added and heterogeneity in responses according to household ethnicity. We have not included the results of including a covariate for distance to nearest school, which captures population density and thus sensitivity to distance, as this does not change our results meaningfully.

${ }^{36}$ Calculated as $\frac{0.52+0.43}{0.43} \approx 2.2$. 

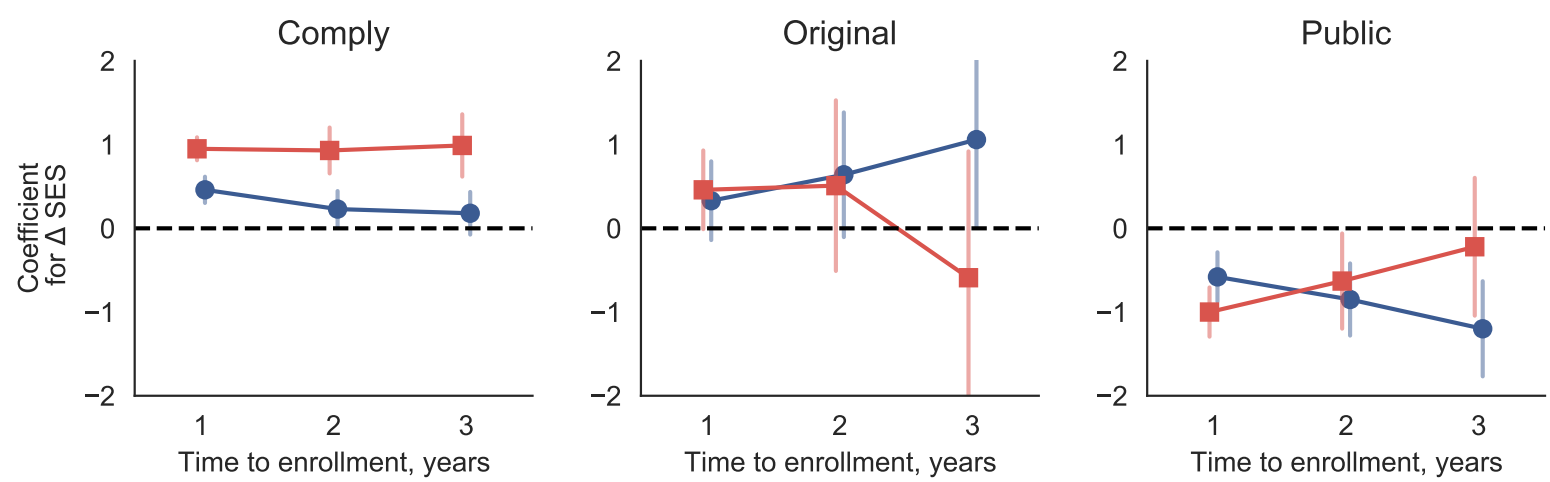

Private
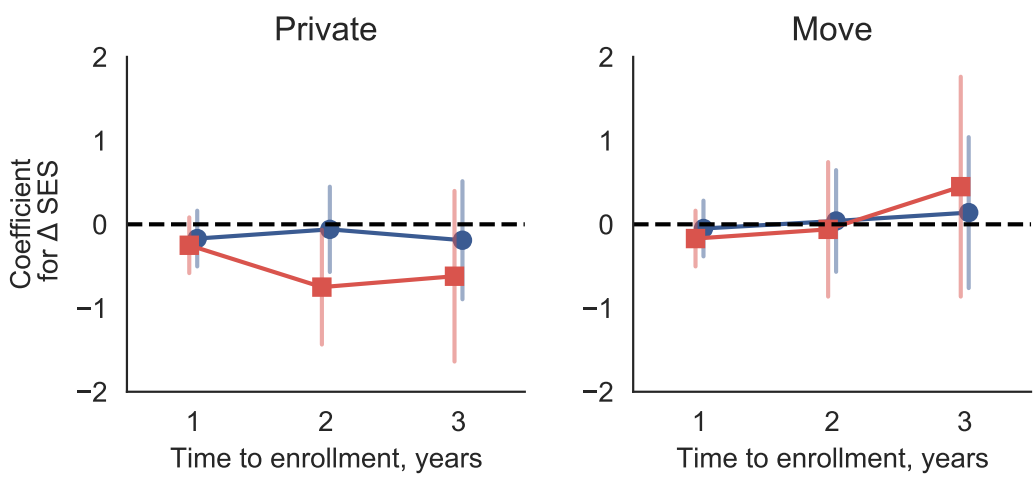

Figure 6: DID-estimates as a function of time to enrollment

The figure displays the estimated sensitivity to changes in school-SES for children at different ages. The younger the child, the longer time to exploit margins. The estimates at 1 year, ie. 5-year-olds, are the same estimates as reported in the middle panel of Table (3). The models are estimated with 'origin-attendance-zone"-year fixed effects. Standard errors are in parentheses and clustered by municipality.

Time to enrollment If households want to defy assignment to a specific school (or to optin), time may be an important determinant for the options available. For example, the small response along the private school margin found above may be due to parents being unable to get their children on the waiting list. In this case, responses along this margin should be larger for younger children who would enroll later. To investigate the importance of time, we construct two new samples containing children who had 2 or 3 years to enrollment (i.e. they were 4 and 3 years old respectively) at the time of the boundary change. We re-estimate the model with Comply as the outcome for these two samples. To allow for asymmetric responses we once again interact the magnitude of the change in school-SES with an indicator for positive or negative changes. The results from this exercise are illustrated in Figure 6 where the leftmost points, corresponding to 1 year planning horizon, are equal to the compliance estimates reported in panel b) in the middle of Table 3 . Although the estimates for children with a longer timespan before enrollment are less precise, the point estimates suggest that parents act along different margins depending on the time before children reach schooling age. The differencein-difference plots with multiple periods before and after also support this conclusion as the pre-trends seem flat, see Figure B.8c.

If parents are faced with a fall in school-SES, the overall compliance sensitivity is more or 
less independent of the age of the child at the time of boundary change as evidenced by the red points in the top-left panel of Figure 6. However this masks differences in the sensitivity on the different margins, whereby households can defy assignment. The more time to adjust, the more likely are children to enroll in a private school if faced with a negative shock to school-SES. If given less time to adjust, on the other hand, households are more likely to enroll their child in another public school, than the one they were initially assigned to. Though the effects are insignificant, these patterns provide indications that the short time-span in our main estimations constrain parents and therefore explain the lack of response along the private school margin for 5-year-olds. We note that higher use of private school is consistent with the boundary discontinuity analysis which established strong discontinuities in private school enrollment at the boundary, see Section 4.

The birth order of children To assert the validity of our model, we investigate whether children with old siblings respond by enrolling less in the new district and respond more to changes in composition when affected by redrawn boundaries. This pattern would be expected from two separate observations. First, municipalities generally allow younger siblings to enroll in the school of the older sibling, even if attendance boundaries change. This implies that households with older children have strictly more options than those without. Moreover, households with older children will face logistical challenges if the younger child enrolls in another school.

To investigate this heterogeneity, we split our sample according to whether the children in our sample are the oldest child or not. With each of these samples, we re-estimate the model for each of the outcome margins in panel b) in the middle of Table 3. The results are displayed in Table 4. The estimates show that in baseline (with no changes in school-SES between the new and original school) the general compliance is lower for children with older siblings (31 percentage points) vs. those without (40 percentage points). Moreover, while the probability of enrollment in the "original" school falls by 18 percentage points after a boundary change for those without siblings, the corresponding fall for those with older siblings is 5 percentage points and insignificant. The results confirm our expectation that children with older siblings to a larger degree enroll in the original school following a change in boundaries than children without older siblings. The likely explanation is that the original school is where their older sibling(s) enrolled.

Those households, who already have children in school, are more responsive to positive changes in school-SES (parameter of 0.52) than those who families with no older children (parameter of 0.38) in terms of compliance while there is no difference in responsiveness to negative schools ( 0.97 and 0.94 respectively). Yet, the differences between the two groups of households are insignificant for both positive and negative shocks.

When it comes to enrolling in other public schools, it may be more inconvenient for households to choose another school, if an older child is not already enrolled. Correspondingly, we 
Table 4: Results, split by being an older child

\begin{tabular}{|c|c|c|c|c|c|}
\hline & Comply & Original & Public & Private & Move \\
\hline & \multicolumn{5}{|c|}{ - Subsample: No older siblings - } \\
\hline \multirow[t]{2}{*}{$\mathrm{T} \times$ Post } & 0.40 & -0.18 & -0.21 & -0.03 & 0.01 \\
\hline & $(0.04)$ & $(0.05)$ & $(0.03)$ & $(0.03)$ & $(0.02)$ \\
\hline \multirow[t]{2}{*}{$\Delta$ Dist $\times$ Post } & -0.04 & -0.01 & 0.06 & -0.02 & 0.01 \\
\hline & $(0.02)$ & $(0.02)$ & $(0.03)$ & $(0.03)$ & $(0.02)$ \\
\hline \multirow[t]{2}{*}{$\Delta^{+} \mathrm{SES} \times$ Post } & 0.38 & 0.25 & -0.22 & -0.23 & -0.17 \\
\hline & $(0.45)$ & $(0.39)$ & $(0.39)$ & $(0.33)$ & $(0.20)$ \\
\hline \multirow[t]{2}{*}{$\Delta^{-} \mathrm{SES} \times$ Post } & 0.94 & 0.49 & -1.13 & -0.24 & -0.05 \\
\hline & $(0.19)$ & $(0.31)$ & $(0.18)$ & $(0.29)$ & $(0.17)$ \\
\hline \multirow[t]{2}{*}{$\mathrm{N}$} & 20,218 & 20,218 & 20,218 & 20,218 & 20,218 \\
\hline & \multicolumn{5}{|c|}{ - Subsample: Have older sibling - } \\
\hline \multirow[t]{2}{*}{$\mathrm{T} \times$ Post } & 0.31 & -0.05 & -0.21 & -0.04 & -0.01 \\
\hline & $(0.03)$ & $(0.04)$ & $(0.04)$ & $(0.02)$ & $(0.03)$ \\
\hline \multirow[t]{2}{*}{$\Delta$ Dist $\times$ Post } & -0.05 & 0.01 & 0.05 & -0.01 & 0.01 \\
\hline & $(0.03)$ & $(0.02)$ & $(0.02)$ & $(0.01)$ & $(0.01)$ \\
\hline \multirow[t]{2}{*}{$\Delta^{+}$SES $\times$Post } & 0.52 & 0.43 & -0.89 & -0.09 & 0.03 \\
\hline & $(0.21)$ & $(0.34)$ & $(0.44)$ & $(0.18)$ & $(0.15)$ \\
\hline \multirow[t]{2}{*}{$\Delta^{-}$SES $\times$Post } & 0.97 & 0.43 & -0.90 & -0.24 & -0.26 \\
\hline & $(0.25)$ & $(0.38)$ & $(0.49)$ & $(0.34)$ & $(0.15)$ \\
\hline $\mathrm{N}$ & 21,882 & 21,882 & 21,882 & 21,882 & 21,882 \\
\hline
\end{tabular}

The table shows the results of splitting the sample according to whether the child is an older child or not. The models are estimated with 'origin-attendance-zone"-level-year fixed effects. Standard errors are in parentheses and clustered on the "origin-attendance-zone"-level.

find that households without older children are 26 percent more sensitive along this margin when experiencing a negative shock to school-SES (-1.13/-0.90). However, when the shock to school-SES is positive, households with older siblings are more responsive. This implies that households with older children exploit the opportunity to opt-in to a higher school-SES when afforded to them, even though the older sibling may be enrolled in another school.

Composition changes for treatment and control groups The validity of our differencein-difference design requires both that the treatment and control groups have approximately identical trends and that the control and treatment groups do not change composition over time. We examine differences in the two groups by measuring whether children with different levels of household-SES vary in their exposure to boundary changes and whether the average household-SES changes over time in response to these changes. Table 5 presents estimates from regression models using Eq. (3) where we limit our sample to two years prior and after boundary changes. From column (1) in the table, we see by inspecting the coefficient for $T \times$ Post that being exposed to a boundary change cannot predict household-SES. This conclusion holds regardless of whether or not we include changes in distances at the household level, see column (2). In column columns (3)-(6) we add the change in school-SES to the model. An inspection of the coefficients for change in school-SES shows that these are neither predictive of 
household-SES before reallocation (e.g. $\triangle$ SES) nor does it lead to changes in the average SES after changes (e.g. $\triangle \mathrm{SES} \times$ Post). We note that the model with a continuous measure of SES finds a weak relationship before reallocation between change in school-SES and householdSES, see columns (5)-(6). The results of Table 5 lead us to conclude that our results are not driven by changes to household composition within attendance zones, neither initially, nor over time.

Comparing compliance for treatment and control groups Another worry is that our measured difference of change in compliance is driven by pre-existing differences in compliance in the original school when comparing the treatment and control units. These differences are not captured in our differences-in-differences setup where we maintain the outcome is enrollment in the newly assigned school. This could be problematic if baseline compliance is systematically higher for those receiving a positive treatment, as it could explain why compliance with the new school is higher. This can be investigated by inspecting the coefficients on the change to school composition, $\Delta Q_{s s^{\prime}}$ in model (3), i.e. without interacting with Post. We show the full set of estimates for the various outcome margins in Table 3 in Appendix Table B.3. When inspecting the baseline variables in Table B.3, i.e. not interacted with Post, it is evident that the coefficient for baseline compliance in the original school is negatively correlated with the change in socioeconomic status $(\rho=-0.59)$. If pre-existing differences in compliance between the control and treatment group were driving our results we would expect a positive correlation. As the correlation is negative, we may in fact be underestimating the effect.

To further address this issue and to assess the existence of flat pre-trends, we redefine our outcome variable to whether children are enrolled in their designated school at the age of 7 . In other words, the variable takes the value of one for non-transferred children enrolled in their original (and unchanged) school as well as for children living in transferred parcels before the boundary change. For children in transferred parcels after the boundary change, the variable takes the value of one if they are enrolled in their new school. The results of this exercise are shown in Appendix Figure B.7. We observe completely flat pre-trends for negative changes in school-SES. For positive changes, we observe an insignificant but slightly rising pre-trend. This trend, however, completely reverses at the time of the boundary change. If anything, this would mean that we underestimate the behavioral response.

A drawback of this alternative compliance measure is that households at treated addresses react to different schools before and after treatment. This change in affiliation makes it hard to interpret the change in terms of school-SES at the time of treatment. We, therefore, regard this measure of compliance as a check of robustness rather than including it in the main analysis.

Spillovers to untreated One concern with our econometric approach is that there may be spillovers to children that are not reassigned to another school. For instance, children in the original district (who are used as a control in our main specification) also experience a change 
Table 5: Selection in socioeconomic status related to boundary changes.

\begin{tabular}{|c|c|c|c|c|c|c|}
\hline & (1) & (2) & (3) & (4) & (5) & (6) \\
\hline \multirow[t]{2}{*}{$\mathrm{T}$} & 0.01 & 0.01 & -0.00 & 0.00 & 0.01 & 0.01 \\
\hline & $(0.02)$ & $(0.02)$ & $(0.02)$ & $(0.02)$ & $(0.02)$ & $(0.02)$ \\
\hline \multirow[t]{2}{*}{$\mathrm{T} \times$ Post } & -0.01 & -0.01 & 0.00 & -0.00 & -0.01 & -0.01 \\
\hline & $(0.02)$ & $(0.02)$ & $(0.02)$ & $(0.02)$ & $(0.02)$ & $(0.02)$ \\
\hline \multirow[t]{2}{*}{$(\Delta \mathrm{SES}>0.1)$} & & & 0.06 & 0.05 & & \\
\hline & & & $(0.03)$ & $(0.04)$ & & \\
\hline \multirow[t]{2}{*}{$(\Delta$ SES $>0.1) \times$ Post } & & & -0.06 & -0.05 & & \\
\hline & & & $(0.03)$ & $(0.03)$ & & \\
\hline \multirow[t]{2}{*}{$(\Delta \mathrm{SES}<-0.1)$} & & & -0.02 & -0.02 & & \\
\hline & & & $(0.03)$ & $(0.03)$ & & \\
\hline \multirow[t]{2}{*}{$(\Delta \mathrm{SES}<-0.1) \times$ Post } & & & -0.00 & -0.01 & & \\
\hline & & & $(0.03)$ & $(0.03)$ & & \\
\hline \multirow[t]{2}{*}{$\Delta \mathrm{SES}$} & & & & & 0.20 & 0.18 \\
\hline & & & & & $(0.09)$ & $(0.09)$ \\
\hline \multirow[t]{2}{*}{$\Delta \mathrm{SES} \times$ Post } & & & & & -0.13 & -0.12 \\
\hline & & & & & $(0.10)$ & $(0.10)$ \\
\hline \multirow[t]{2}{*}{$\Delta$ Dist } & & -0.00 & & 0.00 & & 0.00 \\
\hline & & $(0.01)$ & & $(0.01)$ & & $(0.01)$ \\
\hline \multirow[t]{2}{*}{$\Delta$ Dist $\times$ Post } & & -0.00 & & -0.00 & & -0.00 \\
\hline & & $(0.01)$ & & $(0.01)$ & & $(0.01)$ \\
\hline $\mathrm{N}$ & 48,379 & 48,294 & 48,379 & 48,294 & 48,379 & 48,294 \\
\hline
\end{tabular}

This table contains models of household-SES as the dependent variable using Eq. (3). The models capture whether exposure to and quality of boundary changes are related to either the composition of children in the sample before the change occurred or whether the change in school-SES changed the compositions in our sample. The models are estimated at the child level. Odd model numbers have distance excluded as variables while even-numbered models include them. Columns (1) and (2) estimate the average household-SES given treatment status before and after the change. Columns (3)-(6) predict household-SES when including changes in school-SES induced by boundary changes (where we let untreated units have zero difference). Models (3)-(4) use discrete changes in school SES computed as two thresholds of whether a change in school SES is higher or lower than of 0.1, while models (5)-(6) use continuous changes in school SES. The models are estimated with "origin-attendance-zone"-year fixed effects. Standard errors are in parentheses and clustered on the 'origin-attendance-zone"-level. 
in the composition of newly enrolled students as some of their potential peers no longer enroll. To address such concerns, we construct a matching setup where treated parcels are matched to observations further away. Specifically, we construct a logistic regression model to predict treatment status on the sample of children aged 7 in 2009. The model takes as input the density of the area the child lived in as well as the average SES and NW-share of the household and associated school. We apply the model to compute propensity scores on the sample of children from 2010 to 2015 . We use these scores to match treated children with untreated children without replacement within the same year but who were not in the same municipality. ${ }^{37} \mathrm{We}$ include a total of 10 matches for each treated observation. For the control children in the matched sample, we assign them the district and municipality of the children they are matched to, which is used to respectively compute the fixed effects and cluster standard errors. The use of such fixed effects corresponds to non-parametrically account for the propensity score. Our use of clustering is larger than the matching level, which is recommended by Abadie and Spiess (2021), and thus should be seen as conservative.

Using our unmatched and matched samples, we estimate models of the enrollment in the designated school at age 7, as defined above under Comparing compliance for treatment and control groups. We regress this enrollment measure on continuous measures of changes in school quality using Equation (3). The use of the designated school as enrollment measure ensures a comparable outcome for treatment and control group, which differ more in the matched sample across municipalities than within the same district. ${ }^{38}$ The coefficients for these estimated models are shown in Table B.7, panel A and B for respectively the unmatched and the matched sample. We first note that when using this alternative enrollment measure, the responses of enrollment to changes in school measures are larger than the corresponding estimates in Table 2, for instance, the coefficient for change in SES from column (2) is 1.56 under the alternative measure versus 0.72 . This is due to changing the definition of the outcome variable. Second, the estimates for the matched sample, have the same direction but are smaller in magnitude where the coefficient for change in SES from column (2) is 0.48. Though the control group is different and the identifying assumptions do not allow for unobserved sorting is the present context, the results suggest the same qualitative conclusions of how school quality affects compliance with the assignment. Thus, we conclude that our findings are robust to adjusting for spillovers to the control group.

Household sorting on distance from boundary A concern for policy implications of our findings with respect to boundary changes as a desegregation tool is the external validity of the estimates for households with respect to the distance from the boundary. If households sort on

\footnotetext{
${ }^{37}$ We split the largest municipality, Copenhagen, into three disjoint areas where matching is allowed.

${ }^{38}$ Concretely, in untreated regions it is not clear how to define the counterfactual arrival school, whereas in our main specification it is natural to assign the nearest, which will often correspond to the school that the treated children are allocated to.
} 
the probability of boundary changes and these changes are more likely to occur closer to the border, our estimates will primarily reflect the responses of households closer to the border.

To investigate the responses for households at different distances from the border we combine our spatial data set with the data used for estimating our difference-in-difference models. From the latter we select the treated observations at most two years after the boundary change which are observed in the correct origin district prior to treatment in our spatial data at age five. As in Section 4 we group households in distance bins from the border, where a negative distance implies that the household is on the lower side of a boundary in terms of school-SES. Figure 7a show the distribution of treated households in the combined dataset. As expected, the composition of treated is centered around the boundary, reflecting that most boundary changes are small in terms of changed distance. To investigate the responses as a function of distance from the border we run the following model:

$$
Y_{i b t}=\sum_{d=-D}^{D} \mathbf{1}\left(\text { dist }_{i}=d\right)\left\{\beta^{d}+\gamma^{d} T_{i}+\lambda^{d} \text { Post }_{i t}+\delta^{d} T_{i} \times \text { Post }_{i t}\right\}+\mu_{b t}+\varepsilon_{i t b}
$$

where we use the control group located within a kilometer on the low-SES side of the boundary as the reference category and $\mu_{b t}$ is a boundary-year fixed effect. By interacting with distance from the border, we are effectively embedding our difference-in-difference design in a boundary discontinuity design. Estimates of responses at the left side of the border will reflect positive changes in school-SES as the treated are transferred to the district on the right side of the border (and conversely for bins on the right side of the border). To isolate the effects of school-SES on responses we include controls for distance-to-school changes in case of treatment.

Figure $7 \mathrm{~b}$ displays the resulting estimates graphically. The black circles denote the outcomes of the controls and correspond to a standard boundary discontinuity design. The gray triangles denote the treatment group pre-treatment, which is on average less likely to comply with the assignment and almost uniformly so, regardless of distance. The red squares show the responses post-treatment. Households living far from the boundary appear more responsive than those living closer to the boundary. However, this may reflect that the magnitude of changes in school-SES induced by a boundary change may vary by the size of the original zones. To circumvent this issue of composition we once again interact treatment with the changes in school-SES to obtain an estimate of the marginal responses to school-SES. The resulting estimates are shown in red circles in Figure 7c. The observation-weighted mean is almost exactly 1, reflecting that a change in school-SES of one standard deviation (0.1) diminished compliance by 10 percentage points. Parameters are more precisely estimated for negative changes (right side of boundary) and we observe a rising but insignificant trend in responsiveness as a function of distance. However, if we exchange the boundary-year-fixed effect with a zone-year fixed effect this trend is much less pronounced and the observationweighted mean is 1.2 , reflecting the boundary-fixed effect masks sorting into zones within the 
(a) Treated observations

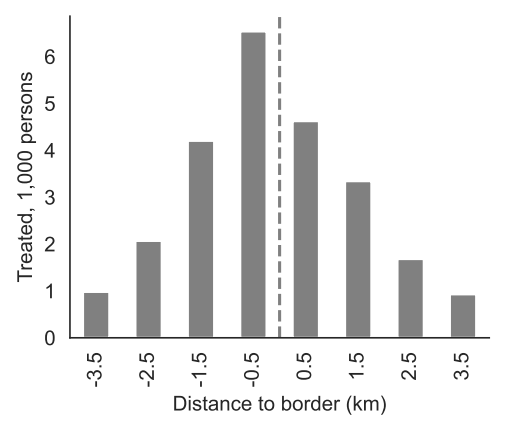

(b) Binary SES change

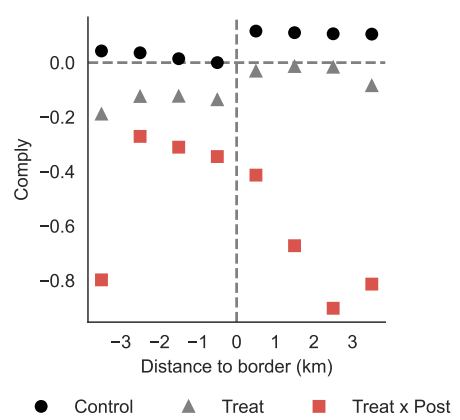

(c) Continuous SES change

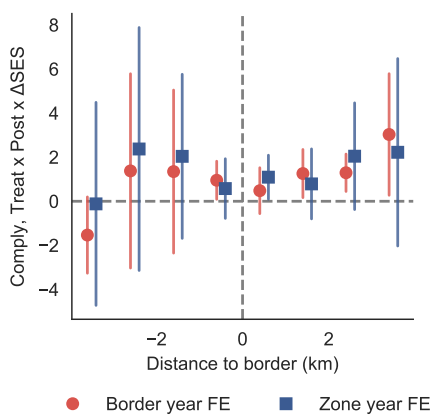

Figure 7: Boundary Discontinuity Difference-in-Difference

Figure 7a shows the number of treated observations in each distance bin. Negative distance to boundary signifies that the household is situated in the district of the two adjacent districts with the lower value of school-SES. Figure $7 \mathrm{~b}$ shows the fully interacted outcomes for the Boundary Discontinuity Difference-in-Difference Design where the outcome is compliance with assigned school in the year of observation. The model is estimated with fixed effects at the boundary-year level and results are centered at the control group in the rightmost bin on the left side of the border. Figure 7c depicts the coefficients on the interaction between binned-distance, change in school-SES, and an indicator for being in the post-treatment group using border-year fixed effects and origin-zone-year fixed effects. Standard errors are clustered on municipality-level.

same boundary region. We find the blue estimates using zone-year fixed effects the most convincing estimates and conclude that while households may be slightly more responsive further away from the border, the main estimates do not only reflect households close to the boundary. If anything, households seeking to increase allocation certainty by living further from a border may be more responsive, leading to an underestimation of the behavioral responses following a boundary change.

To specifically test whether distance to the border is a determining factor we reestimate our main specification in Equation (3) with the original compliance measure on the sample with border distances where we fully interact our variables with distance to the border. We fail to reject the null on the interaction between changes in school characteristics, the Post-indicator and distance to the border with a t-value of $1.39(\mathrm{p}=0.17)$. This supports our previous finding that distance to the border does not seem to be an important factor in predicting household responses to changes in school-SES. ${ }^{39}$

Alternative measure for School Value Added The official measure for School Value Added (SVA) fails to include some obvious control variables. For instance, pre-school test scores are excluded and urbanization is not taken into account. We suspect the presence of substantial unobserved sorting and the SVA estimate may therefore suffer from omitted variable bias. In addition, the measure is quite volatile with a year-on-year correlation in the subject-institution value-added of 0.3. To address these concerns we computed an alternative measure of School

\footnotetext{
${ }^{39}$ In line with expectations we observe that applicants are on average less likely to comply the further from the the boundary. However, this pattern is not a function of the change in school-SES.
} 
Value Added using pupil fixed effects. This approach exploits variation from pupils changing school over time assuming school changes are random. The test scores were measured in different years at lower grade levels, thus the School Value Added reflects the average gain per pupil of changing to a given school. This approach, inspired by Abowd et al. (1999), yielded very similar estimates in our estimates of behavioral responses and did not affect our conclusions.

Household heterogeneity in responses - Ethnicity, Income and Education We finish our analysis of attendance boundary changes by investigating heterogeneity in responses across ethnic groups and components of our SES-index. We replicate our analysis of how responses are heterogeneous in household-SES (from panel c) of Table Table 3) where we use household ethnicity changes in school ethnicity instead. The estimated coefficient of change in enrollment in the new school as a function change in school share of Non-Western ( $\Delta \mathrm{NW} \times$ Post) is slightly higher for native and Western descendants than in the homogeneous model in column 3 of Table 2. However, non-Western households respond significantly less (see coefficient for $\Delta \mathrm{NW}$ $\times$ Post $\times$ NW), which results in the total change in enrollment by Non-Western households to changes in the share in the share of other Non-Western children is small and negligible, see Table B.4 in Appendix B.4.

One worry is that response heterogeneity in our household-SES-index may be dominated by a single variable. To investigate this we estimate our model using average education level in schools and average income. The results are qualitatively unchanged as evidenced in Tables B.5 and B.6. This is not surprising given that the first principal component is highly correlated with these measures. However, we observe that the ratio of the private school margin over total compliance is larger, when we parameterize schools with education rather than our SESindex (For Education:0.40/0.97=41.1 and for household-SES: 0.21/0.72=29.3 ). This mostlikely reflects that our education variable picks out the upper quartile of our household index as evidenced in Appendix Figure A.1. Thus a change in average education is equivalent to an increase in the share of high-SES households enrolled in the school rather than a uniform increase in household-SES.

\section{Implications for policy}

To illustrate the implications of our findings for the efficacy of boundary changes as a desegregation policy we embed our causal estimates in a simplified simulation model. Our estimates are inherently reduced form which limits the scope for simulating enrollment responses to policies. Our estimates measure the change in behavior following a mechanical change in school characteristics using previous cohorts as a measure of the magnitude of the change. Thus, the estimates reflect both preferences as well as the admission expectations and constraints of relevant schools. School enrollment is inherently a coordination game, where parents choose 
enrollment based on the expected enrollment of other households in a given cohort. In the end, the policymaker is interested in the equilibrium where both transferred households and households in the receiving district have correct expectations of enrollment behavior. While some of this coordination is baked into our reduced-form estimates we cannot easily disentangle these higher-order coordination responses. We, therefore, model the initial effects on the treated children and ignore higher-order coordination responses and responses of households in receiving districts. Accordingly, the simulation results should be interpreted with caution and solely convey the magnitude of the direct policy inefficacy due to behavioral effects.

We model an environment with two public schools. We do not distinguish between the margins of responses and therefore assume a single outside option, distinct from the two schools, which we assume is available to all households. The total population of households has unit mass and the attendance zones have equal sizes with a mass of one-half. As we find no clear evidence in Section 5.4 that distance from the boundary explains heterogeneity in responses we abstain from modeling the geography further. Households are divided into SES-quartiles where households receive an SES-index in the middle of their quartile interval. To investigate the importance of initial levels of segregation, we construct distributions of neighboring school attendance zones by computing a range of feasible combinations of the four quartiles in the two districts. For each distribution of households, we calculate the mean SES of the families in the attendance zone. By construction, the absolute difference in our measure of mean attendance zone SES can take values between 0 and 0.5 , where the former represents full desegregation and the latter represent full segregation. ${ }^{40}$ To compute school-SES from residential-SES we estimate baseline compliance in linear probability models for each SES-quartile, with compliance on the left side and residential SES on the right. The linear probability models are estimated using all available data from the years 2008-2015. We use these models to predict baseline compliance levels and in turn, compute the baseline difference in school-SES which represents the initial equilibrium.

We perform two kinds of policy experiments. First, we model a transfer of 10 percent of the parcels in the low-SES attendance zone to the high-SES attendance zone and calculate the resulting SES-change in the high-SES school. Next, we model a transfer of 10 percent transfer from the high-SES school to the low-SES school and calculate the resulting SES-change in the low school. We assume that households observe the difference in baseline school-SES across the two districts and that the transferred parcels are randomly drawn from the district. ${ }^{41}$ Based on the baseline differences in school-SES, we construct three scenarios. First, we assume

\footnotetext{
${ }^{40}$ The maximal difference follows from the fact that the most segregated case is where the bottom half of households are all in one attendance zone with mean SES $=0.25$; accordingly the two top quartiles reside in the other attendance zone which therefore has a mean SES of 0.75. The difference in residential-SES between the two zones is therefore 0.5 .

${ }^{41}$ This implies that we do not need to model the behavior in the sending district as school-SES remains unchanged.
} 
limited compliance which is independent of school-SES. Second, we assume that the response to school differences for compliance rates is homogeneous across household-SES, using the estimates of the top left column in Table 3. Third, we assume heterogeneity in compliance rates based on the estimates in the bottom left column of Table 3 . We restrict predicted compliance by truncating values to reside within the unit interval. ${ }^{42}$

The results of these simulations are shown in Figure 8. Firstly, we consider the effect of moving low-SES households to high-SES schools. In Figure 8a we model the response under the assumption of no changes in school distances whereas Figure $8 \mathrm{~b}$ shows the simulated responses assuming an increase in distance to the new school of 2 kilometers compared to the original school. Assuming that households enroll their child according to the national average (70 percent enrollment), the dashed lines show the expected fall in the school-SES when transferring low-SES households to the new attendance zone. However, our analysis shows that the compliance rate after reassignment is on average 33 pct. when there is no change of distance and 23 pct. when the change of school distance is $2 \mathrm{~km}$. Taking distance into account, the change in school-SES is much less pronounced. However, once we allow the behavior to depend on the composition of the receiving school, the effects resemble the expected effects as evidenced by the red and blue lines. This reflects that incoming households receive a positive shock to school-SES and therefore choose to opt-in to a larger degree than what the baseline compliance would suggest. The difference between Figure $8 \mathrm{a}$ and Figure $8 \mathrm{~b}$ shows that the wedge between expected and realized changes in school-SES is increased by the introduction of distance.

We now consider transferring high-SES households to low-SES schools in Figures 8c and 8d. Naturally, the more initial residential segregation, the larger is the incentive to transfer parts of the affluent attendance zone to the less affluent one. This explains the high slope of the baseline-compliance scenario in Figure 8 (in solid black). Taking baseline compliance of transferred households into account, the solid black line again shows that expected changes in school-SES are smaller than the mechanical change assuming baseline compliance rates of 70 percent. Assuming homogeneous behavioral responses to the change in school-SES, the slope is still positive for the first half of the range of residential segregation. In other words, the policy succeeds in changing the social composition of the low SES-school. However, at sufficiently high levels of residential segregation between attendance zones, the expected gain is reduced. This is due to the difference in baseline school-SES. When this difference becomes large, households exploit the outside option. At the extreme end of the segregation scale, the expected gain is zero. In the scenario with heterogeneous responses, the inefficacy of redrawing boundaries becomes even more pronounced. As in the case with homogeneous

\footnotetext{
${ }^{42}$ Though compliance is estimated in a linear probability model we restrict the predicted compliance to be between zero and one. The assumption of baseline compliance, therefore, is important as it limits the degree of response in either direction.
} 
(a) Low to high SES; no change of distance

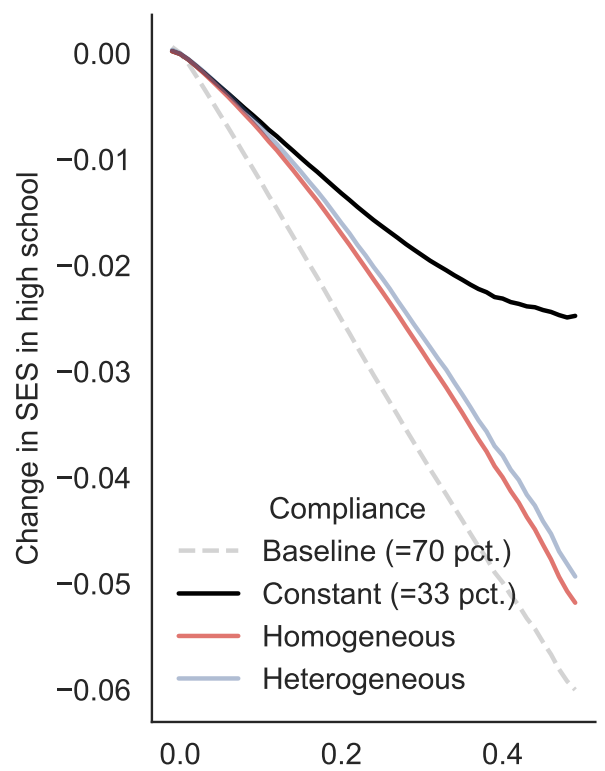

Prior residential segregation (diff. school SES) (b) Low to high SES; change of distance $2 \mathrm{~km}$

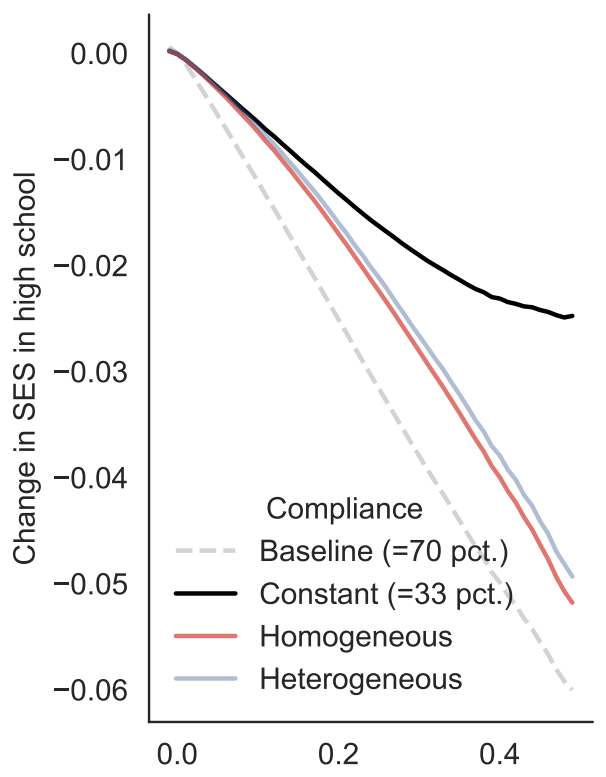

Prior residential segregation (diff. school SES)

(c) High to low SES; no change of distance

(d) High to low SES; change of distance $2 \mathrm{~km}$

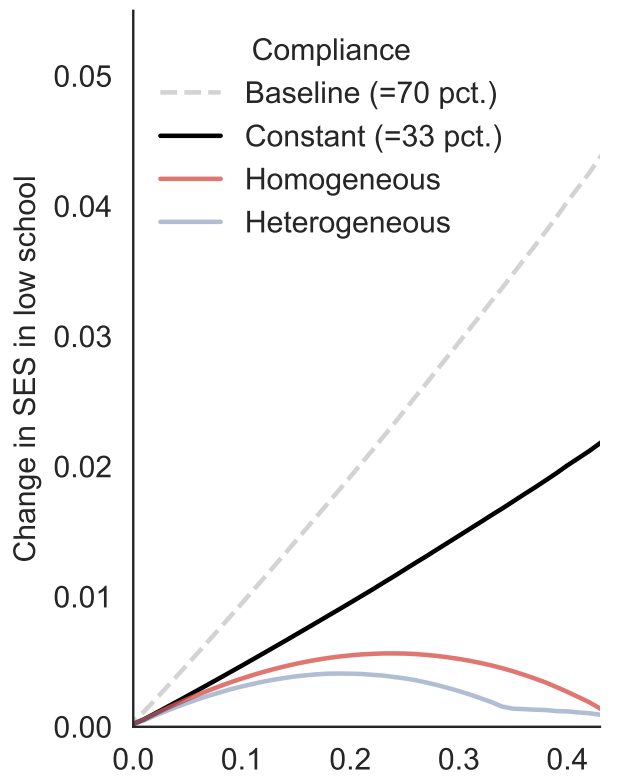

Prior residential segregation (diff. school SES)

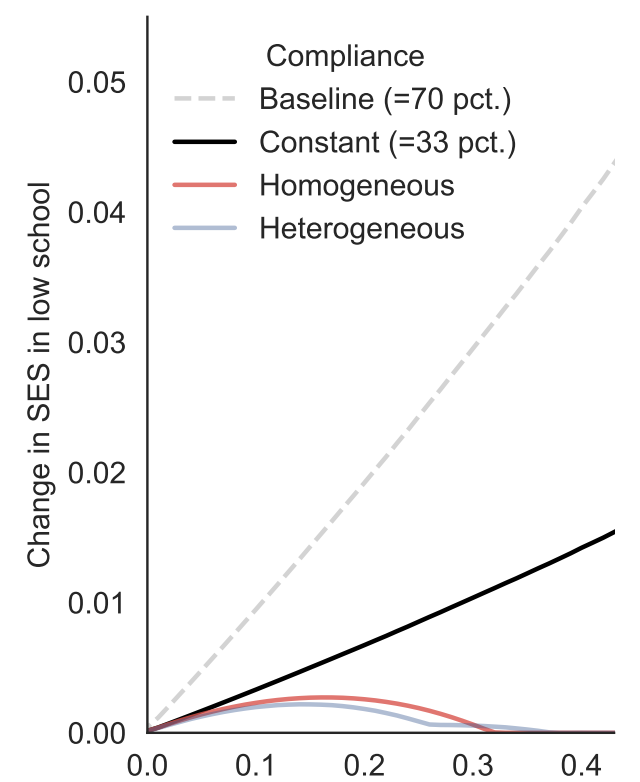

Prior residential segregation (diff. school SES)

Figure 8: Simulated policy efficiency with and without behavioral responses

The figure displays the result on school SES from a change in an attendance boundary. The panels in the top are when parcels from the low SES attendance zone are moved to the high SES attendance zone and the bottom reversed. Figures $8 \mathrm{a}$ and $8 \mathrm{c}$ shows the simulated under responses assuming zero change in the distance. Figures $8 \mathrm{~b}$ and $8 \mathrm{~d}$ shows the simulated responses assuming a $2 \mathrm{~km}$ increase in distance to the new school over the original school. Each location on the x-axis represents a simulated environment with a given level of residential segregation. We refer to the main text for more details. 
responses, household compliance fall with the baseline difference between the two schools. The high-SES households, however, opt-out at smaller changes to school-SES and the mass of complying students become socioeconomically weaker, further negating the expected gains to school-SES in the challenged school. In the words of Okun (1975), the policy of changing attendance zone boundaries is akin to a leaky bucket; the policy does not achieve the intended desegregation, as households exploit the availability of outside options. The simulations where we move students from the disadvantaged school to the affluent one, show that there is scope for boundary changes where poorer areas are included in richer areas. However, this is contingent on the number of incoming students not being too large to affect the behavior of the households already in the receiving school. Additionally, in our model the transfer does not change the school-SES of the sending district. If the goal is to raise school-SES in a less affluent school, our simulations therefore suggest that the scope of boundary changes as a desegregation tool is limited. Where the degree of segregation is large, i.e. where desegregation may be most desirable, a policy of boundary changes moving high-SES households to disadvantaged schools is almost completely ineffective. The implication is that boundary changes are only effective at increasing school-SES in already desegregated areas.

\section{Conclusion}

Policy-makers who aim to balance school composition can manipulate the school boundaries and choose which children are supposed to enroll where. But the efficacy of this strategy, as with most other public interventions, depends on the behavioral responses of the subjects of the policy. We document that parents react to redistricting by opting out of their assigned school by choosing other public schools and to some extent use private schools and relocation. Households with high socioeconomic status drive the responses, which implies that the "leakage" occurs in the top tail of the distribution. Consequently, if policy-makers want to minimize segregation across schools they must do so under the constraint that parents have an outside option. Interpreted more generally these findings imply that there are limits to minimize segregation when individuals have an outside option. In other words, there is limited potential for what Durlauf (1996) refers to as associational redistribution. Consequently, our results matter not only for drawing boundaries between schools but are also relevant in a broader sense for designing groups within schools and organizations.

Our results point more generally to the fact that policies which change local school provision to alter the student composition operate under participation constraints. As such, our results imply that there may be limits to scaling up policies such as Moving to Opportunity (e.g Bergman et al., 2020); when low-SES households move in, the high-SES households are more likely to leave, thereby negating the possible peer effects. These policies are often indirectly aimed at redistributing access to skill formation and/or opportunities by altering the structure of social interactions assuming that there are positive effects of more resourceful peers (Sacer- 
dote, 2011). As a consequence, our results have important implications for the extent to which policies aimed at changing social interactions can reduce the high and rising economic inequality observed across nations (Atkinson et al., 2011). This corrosion of policy efficacy may be attributed to the fact that affected individuals themselves care about having resourceful peers and is consistent with our findings that reallocation leads to systematic defiance.

\section{References}

Abadie, A., Spiess, J. 2021. Robust post-matching inference. Journal of the American Statistical Association, 1-13.

Abdulkadiroğlu, A., Pathak, P. A., Schellenberg, J., Walters, C. R. 2020. Do parents value school effectiveness? American Economic Review, 110, 1502-39.

Abdulkadiroğlu, A., Sönmez, T. 2003. School Choice: A Mechanism Design Approach. American Economic Review, 93, 729-747.

Abowd, J. M., Kramarz, F., Margolis, D. N. 1999. High Wage Workers and High Wage Firms. Econometrica, 67, 251-333.

Angrist, J. D., Imbens, G. W., Rubin, D. B. 1996. Identification of causal effects using instrumental variables. Journal of the American statistical Association, 91, 444-455.

Atkinson, A. B., Piketty, T., Saez, E. 2011. Top incomes in the long run of history. Journal of economic literature, 49, 3-71.

Baum-Snow, N., Lutz, B. F. 2011. School desegregation, school choice, and changes in residential location patterns by race. American Economic Review, 101, 3019-46.

Bayer, P., Ferreira, F., McMillan, R. 2007. A Unified Framework for Measuring Preferences for Schools and Neighborhoods. Journal of Political Economy, 115, 588-638.

Bergman, P., Chetty, R., DeLuca, S., Hendren, N., Katz, L., Palmer, C. 2020. Creating moves to opportunity: Experimental evidence on barriers to neighborhood choice.

Bibler, A., Billings, S. B. 2020. Win or lose: Residential sorting after a school choice lottery. Review of Economics and Statistics, 102, 457-472.

Bifulco, R., Ladd, H. F., Ross, S. L. 2009. Public school choice and integration evidence from durham, north carolina. Social Science Research, 38, 71-85.

Billings, S. B., Brunner, E. J., Ross, S. L. 2018. Gentrification and failing schools: The unintended consequences of school choice under nclb. Review of Economics and Statistics, 100, $65-77$. 
Billings, S. B., Deming, D. J., Rockoff, J. 2014. School segregation, educational attainment, and crime: Evidence from the end of busing in charlotte-mecklenburg. The Quarterly Journal of Economics, 129, 435-476.

Bjerre-Nielsen, A., Gandil, M. H. 2018. Privacy in spatial data with high resolution and time invariance.

Black, S. E. 1999. Do Better Schools Matter? Parental Valuation of Elementary Education. The Quarterly Journal of Economics, 114, 577-599.

Black, S. E., Devereux, P. J. 2011. Recent developments in intergenerational mobility. 4, Elsevier B.V. 1487-1541.

Borghans, L., Golsteyn, B. H. H., Zölitz, U. 2015. Parental preferences for primary school characteristics. B.E. Journal of Economic Analysis and Policy, 15, 85-117.

Burgess, S., Greaves, E., Vignoles, A., Wilson, D. 2011. Parental choice of primary school in England: what types of school do different types of family really have available to them?. Policy Studies, 32, 531-547.

Burgess, S., Greaves, E., Vignoles, A., Wilson, D. 2015. What Parents Want: School Preferences and School Choice. The Economic Journal, 125, 1262-1289.

Calsamiglia, C. 2013. Matching practices for elementary and secondary schools - spain. Matching-in-Practice Country Profile 16.

Cantillon, E. 2017. Broadening the market design approach to school choice. 1-16.

Chavez, H., Agrelo, R., Candal, C. S. 2012. Argentina. Balancing freedom, autonomy and accountability in education, 3, 19-33.

Clapp, J. M., Nanda, A., Ross, S. L. 2008. Which school attributes matter? the influence of school district performance and demographic composition on property values. Journal of Urban Economics, 63, 451-466.

Clotfelter, C. T. 1976. School desegregation," tipping," and private school enrollment. Journal of Human Resources, 28-50.

Coleman, J. S., Campbell, E. Q., Hobson, C. J., McPartland, J., Mood, A. M., Weinfeld, F. D., York, R. L. 1966. Equality of educational opportunity..Technical report, U.S. Department Of Health, Education \& Welfare, Office of Education, Report Number 0E-36001.

Durlauf, S. N. 1996. A theory of persistent income inequality. Journal of Economic Growth, 1, 75-93. 
Echenique, F., Yenmez, M. B. 2015. How to control controlled school choice. American Economic Review, 105, 2679-94.

Ehlers, L., Hafalir, I. E., Yenmez, M. B., Yildirim, M. A. 2014. School choice with controlled choice constraints: Hard bounds versus soft bounds. Journal of Economic Theory, 153, 648683.

Epple, D., Figlio, D., Romano, R. 2004. Competition between private and public schools: Testing stratification and pricing predictions. Journal of Public Economics, 88, 1215-1245.

Fack, G., Grenet, J. 2010. When do better schools raise housing prices? Evidence from Paris public and private schools. Journal of Public Economics, 94, 59-77.

Gibbons, S., Machin, S., Silva, O. 2013. Valuing school quality using boundary discontinuities. Journal of Urban Economics, 75, 15-28.

Gillies, S. et al. 2007-. Shapely: manipulation and analysis of geometric objects.

Hagberg, A. a., Schult, D. a., Swart, P. J. 2008. Exploring network structure, dynamics, and function using NetworkX. Proceedings of the 7th Python in Science Conference (SciPy2008), 836, 11--15.

Hastings, J. S., Kane, T. J., Staiger, D. O. 2009. Heterogeneous preferences and the efficacy of public school choice. Working paper.

Hiller, V., Tercieux, O. 2013. Matching practices in secondary schools-france. MiP Country Profile, 16.

Hvidovre. 2019. Helhedsplan for fremtidens skolestruktur i Hvidovre Kommune.Technical report, Hvidovre Kommune.

Imberman, S. A., Lovenheim, M. F. 2016. Does the market value value-added? evidence from housing prices after a public release of school and teacher value-added. Journal of Urban Economics, 91, 104-121.

Jones, E., Oliphant, T., Peterson, P. et al. 2001-. SciPy: Open source scientific tools for Python. [Online; accessed Jan. 10, 2018].

Kane, T. J., Riegg, S. K., Staiger, D. O. 2006. School quality, neighborhoods, and housing prices. American law and economics review, 8, 183-212.

Lubotsky, D., Wittenberg, M. 2006. Interpretation of regressions with multiple proxies. The Review of Economics and Statistics, 88, 549-562.

Manlove, D. 2013. Matching practices for primary and secondary schools - scotland. Matching-in-Practice Country Profile 12. 
McKinney, W. 2010. Data Structures for Statistical Computing in Python. Proceedings of the 9th Python in Science Conference, 1697900, 51-56.

Merlino, L. P., Nicoló, A. 2012. Matching practices for secondary schools-italy. MiP country profile, 6 .

Monarrez, T. 2021. School attendance boundaries and the segregation of public schools in the us. Working paper.

Monarrez, T., Kisida, B., Chingos, M. M. 2020. The effect of charter schools on school segregation. American Economic Journal: Economic Policy.

Nechyba, T. J. 2000. Mobility, targeting, and private-school vouchers. American Economic Review, 90, 130-146.

OECD. 2016. Education in china - a snapshot.Technical report.

Okun, A. M. 1975. Equality and efficiency, the big tradeoff.

Olsen, A. L., Kyhse-Andersen, J. H., Moynihan, D. 2020. The unequal distribution of opportunity: A national audit study of bureaucratic discrimination in primary school access. American Journal of Political Science.

Pedregosa, F., Varoquaux, G., Gramfort, A., Michel, V., Thirion, B., Grisel, O., Blondel, M., Prettenhofer, P., Weiss, R., Dubourg, V., Vanderplas, J., Passos, A., Cournapeau, D., Brucher, M., Perrot, M., Duchesnay, É. 2012. Scikit-learn: Machine Learning in Python. Journal of Machine Learning Research, 12, 2825-2830.

Rangvid, B. S. 2009. School choice, universal vouchers and native flight from local schools. European Sociological Review, 26, 319-335.

Riedel, A., Schneider, K., Schuchart, C., Weishaupt, H. 2010. School choice in german primary schools: How binding are school districts? 1/schulwahl in deutschen grundschulen: Wie verbindlich sind schulbezirke? Journal for educational research online, 2, p. 94.

Rossell, C. H. 1975. School desegregation and white flight. Political Science Quarterly, 90, $675-695$.

Sacerdote, B. 2011. Peer Effects in Education: How might they work, how big are they and how much do we know Thus Far?. 3, Elsevier B.V. 1st edition, 249-277.

Saporito, S., Sohoni, D. 2007. Mapping educational inequality: Concentrations of poverty among poor and minority students in public schools. Social Forces, 85, 1227-1253.

StataCorp. 2017. Stata Statistical Software: Release 15. 


\section{A Construction of SES index}

This appendix outlines how we construct our socio-economic index. We describe our approach of reducing a set of socio-economic variables to a single socio-economic index (SES index henceforth) and we evaluate the index' performance.

We construct our SES-index by choosing the first variable resulting from a principal component analysis (PCA) based on the following variables:

- INC: We calculate the market income rank of all adults in the population. We select the highest income rank observed in a household.

- LCE: A dummy which takes the value of one if an adult in a household has completed a long cycle education.

- NE: A dummy which takes the value of one if an adult in a household has not completed in education beyond primary school or have no registered education.

- EMP: A dummy which takes the value of one if an adult in a household is employed.

We select the first component of the PCA. This leads to the following index:

$$
S E S=0.62 I N C+0.38 L C E-0.44 N E+0.53 E M P,
$$

where all variables have been standardized to their corresponding z-scores. This index accounts for 47 pct. of the variation in the four variables. The SES-index applied in our paper is the population ranks of SES, as such it is uniformly distributed on the unit interval.

To get a sense of the mapping between the underlying variables we calculate averages of the underlying variables in percentiles of the SES-index. The results are displayed in Figure A.1. While this is a very simple index we find that this component is intuitive. In the bottom of the distribution almost all households have an uneducated parent and no parent with a high cycle education. In the top 75 percent of the distribution no household contain an uneducated parent. Income and employment are both rising in the SES-index. Thus we find it safe to assume that the SES-index reflects a true underlying socioeconomic status. 


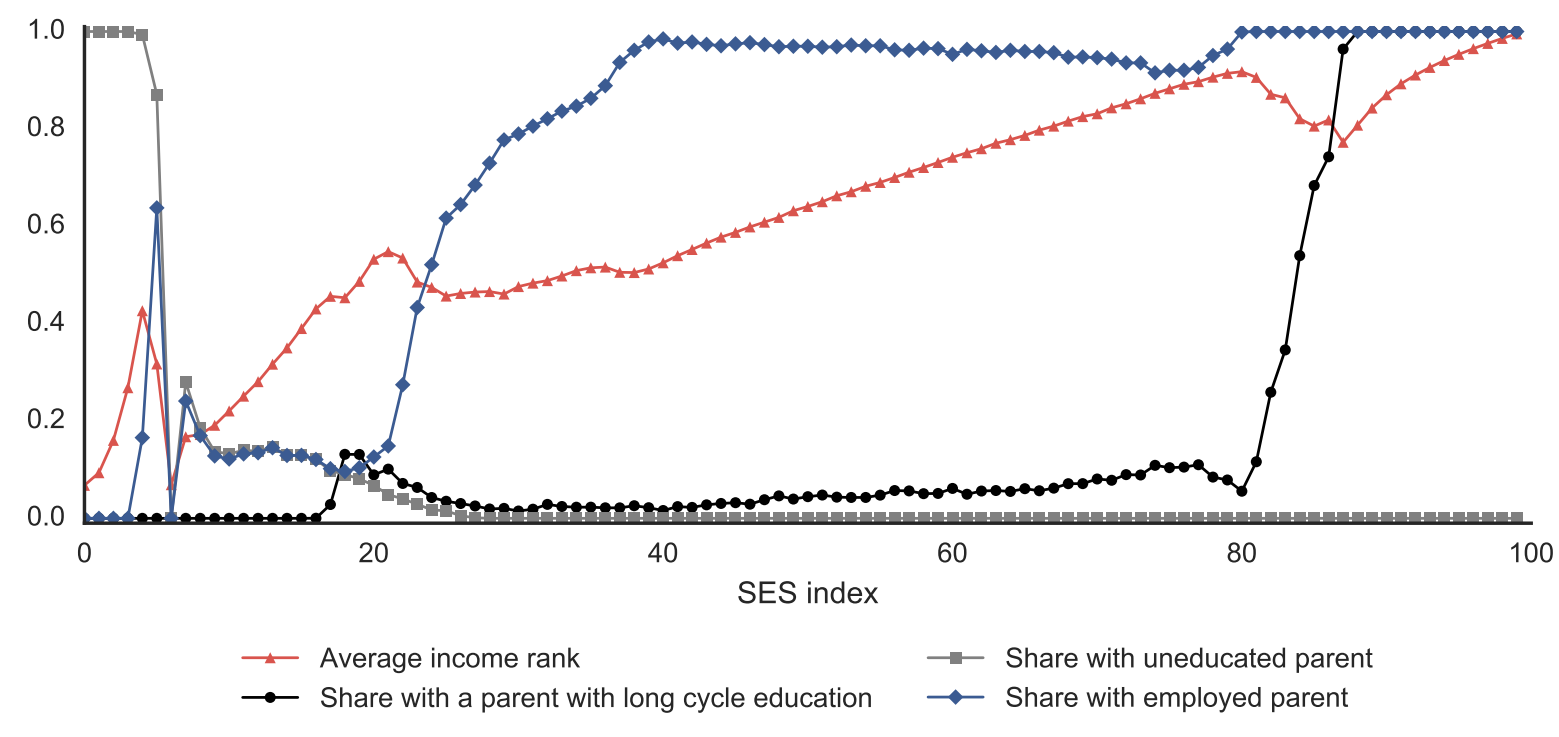

Figure A.1: Average characteristics as a function of SES-index

The figure depicts means of variables used to construct the SES-index. The SES-index is uniformly distributed on the unit interval. Each marker represent the mean of the variable in question within a percentile bin. Income rank is bounded between 0 and 1 . 


\section{B Supplementary tables and plots}

Table B.1: Treatment propensity and characteristics for municipalities and schools

\begin{tabular}{lcc}
\hline \hline & $(1)$ & $(2)$ \\
& Municipal level & Attendance zone level \\
\hline SES (mean) & 0.041 & 0.092 \\
& $(0.346)$ & $(0.161)$ \\
SES (std. dev.) & 0.712 & $(0.551)$ \\
Pop. density (mean) & $(1.731)$ & 0.037 \\
Pop. density (std. dev.) & 0.091 & $(0.010)$ \\
& $(0.029)$ & 0.098 \\
N & -0.121 & $(0.041)$ \\
F.E. & $(0.090)$ & 1083 \\
Clusters & 88 & Municipal \\
\hline \hline
\end{tabular}

This table contains models of the treatment indicator as the outcome of whether. The indicator variable is computed at the attendance boundary level and measures whether the attendance zone has experienced changes to its boundaries over the period 2008-2015. The explanatory variables are descriptive statistics computed at the for municipalities and attendance zone level. 


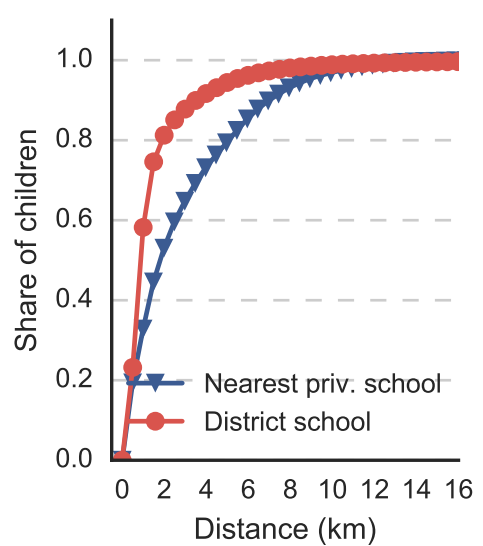

(a) Distance to school

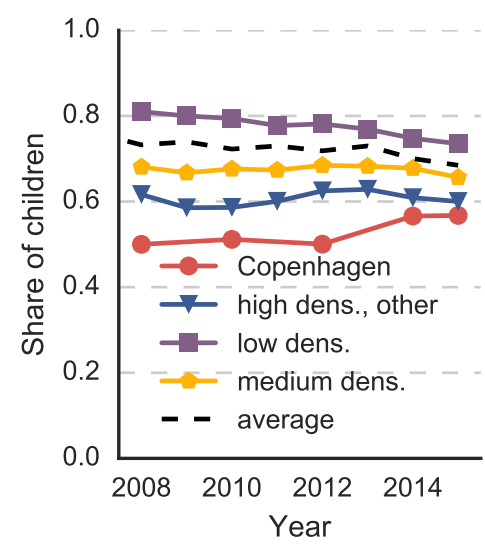

(b) Share in district school

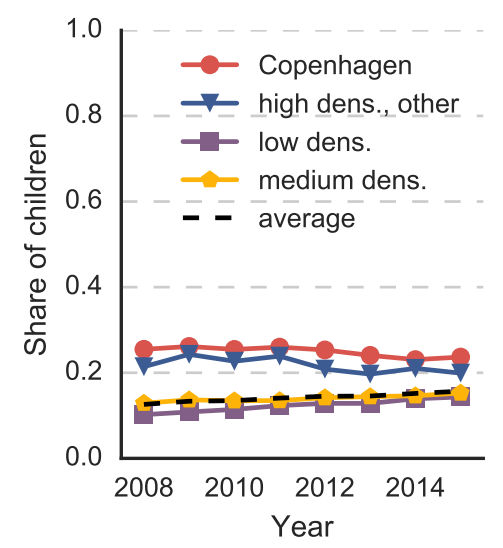

(c) Share in private school

Figure B.1: School distance and enrollment

The figures depict various statistics for distance and enrollment. Figure B.1a shows the cumulative distribution of distance to district school and nearest private school. Figures B.1b and B.1c plots the annual share of children enrolled respectively in the district school and in a private school. The sample consist of all children at the age 7 between 2008 and 2015. For enrollment, the density measures are: low density, less than 1000 per sq. km; medium density, between 1000 and 5000 per sq. km, and; high density, more than 5000 per sq. km.

Public schools

Average $=10.6$

Median $=5.4$

\section{Public schools}

Average $=46.7$

Median $=45.9$

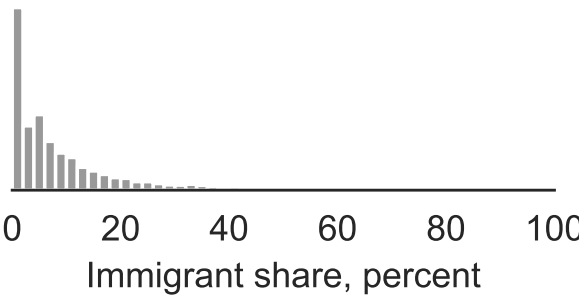

Private schools

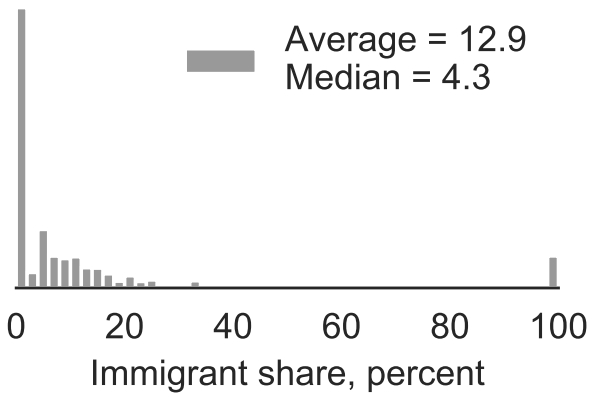

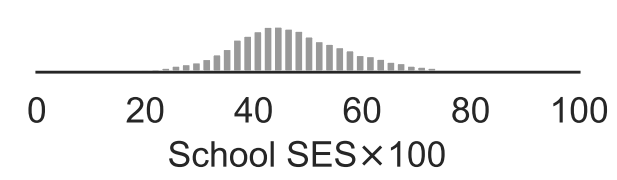

Private schools

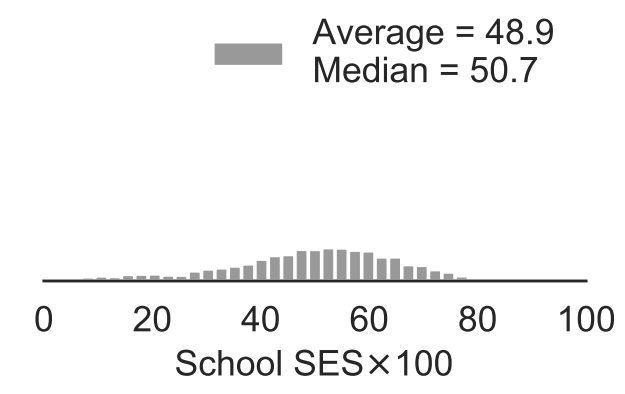

Figure B.2: Distribution of immigrant share and school-SES for private and public schools

The figures depict the distribution of school characteristics for public and private schools for the years 2008-2015. The mean immigrant share and school-SES are are measured for seven-year old children within each school-year. The y-axis are standardized across plots. 
(a) Total non-compliance

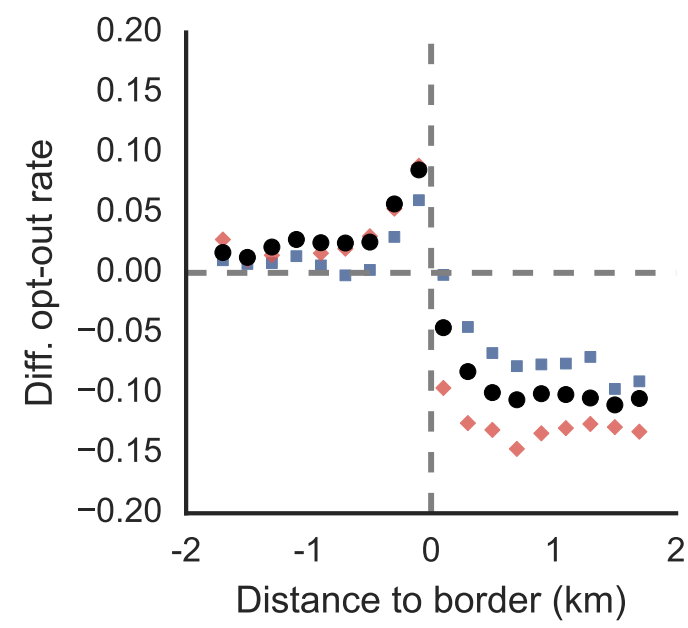

- $\quad$ Full sample, marg. effect:-1.16

- 1st SES-quartile, marg. effect:-0.67

- $\quad$ 4th SES-quartile, marg. effect:-1.47

(c) Private school

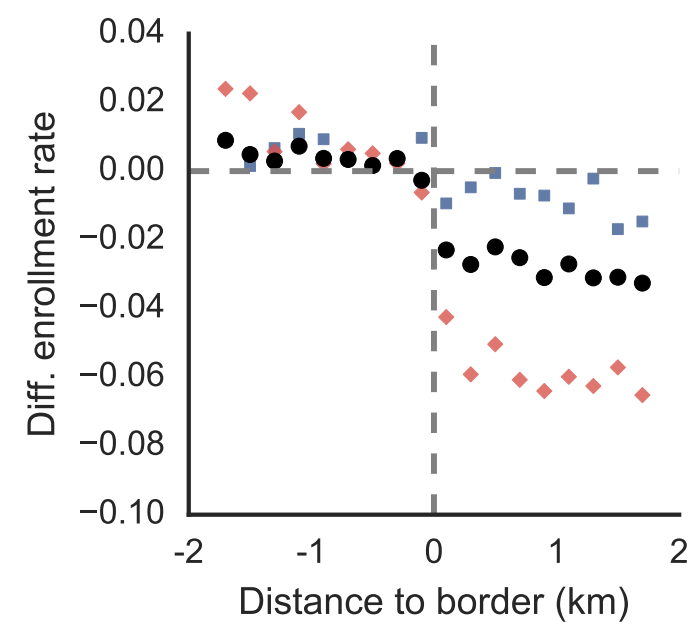

- Full sample, marg. effect:-0.29

- 1st SES-quartile, marg. effect:-0.14

- 4th SES-quartile, marg. effect:-0.69 (b) Other public school

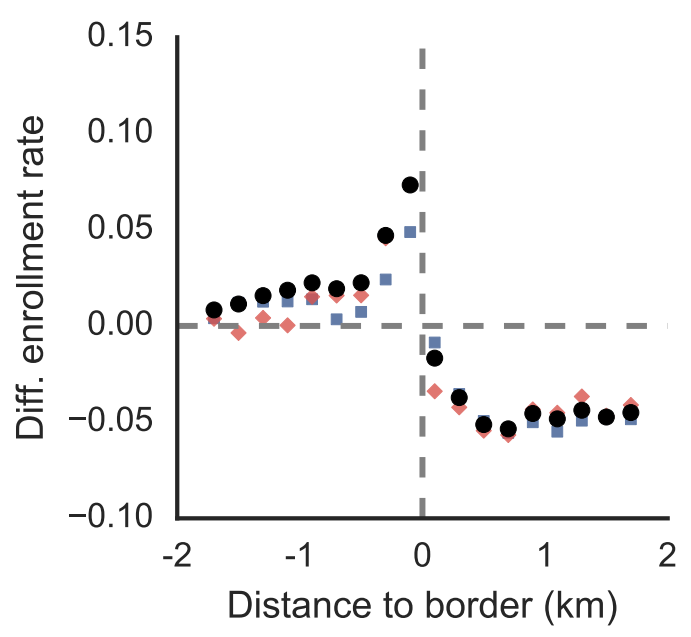

- Full sample, marg. effect:-0.64

- 1st SES-quartile, marg. effect:-0.47

- 4th SES-quartile, marg. effect:-0.52

(d) Move before age 7

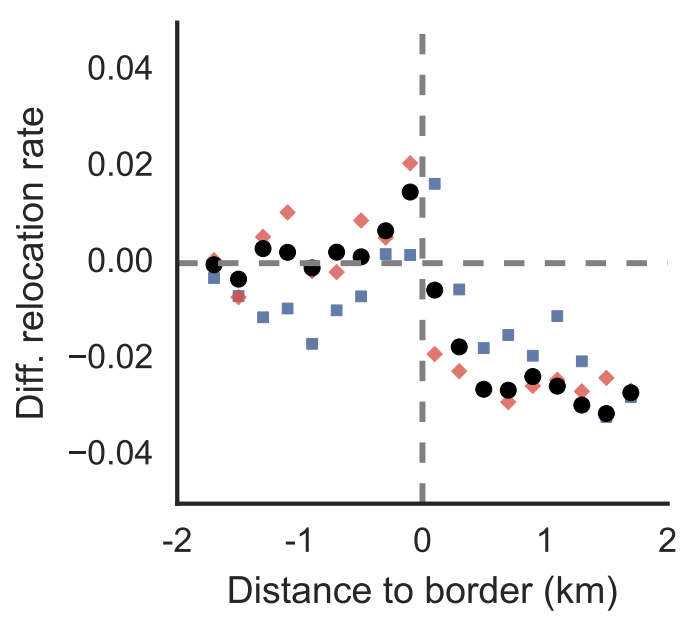

- $\quad$ Full sample, marg. effect:-0.22

- 1st SES-quartile, marg. effect:-0.07

- 4th SES-quartile, marg. effect:-0.24

Figure B.3: Boundary difference in opt-out for low/high SES schools - by household SES 


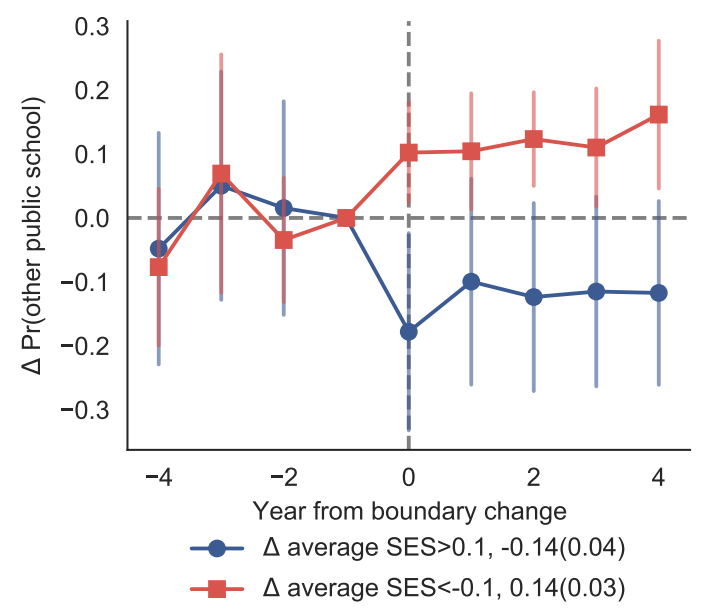

(a) Other public school

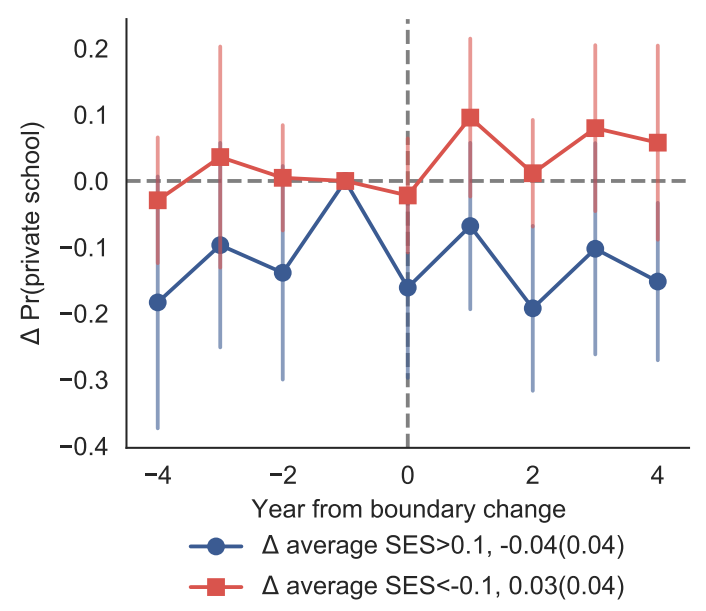

(c) Private school enrollment

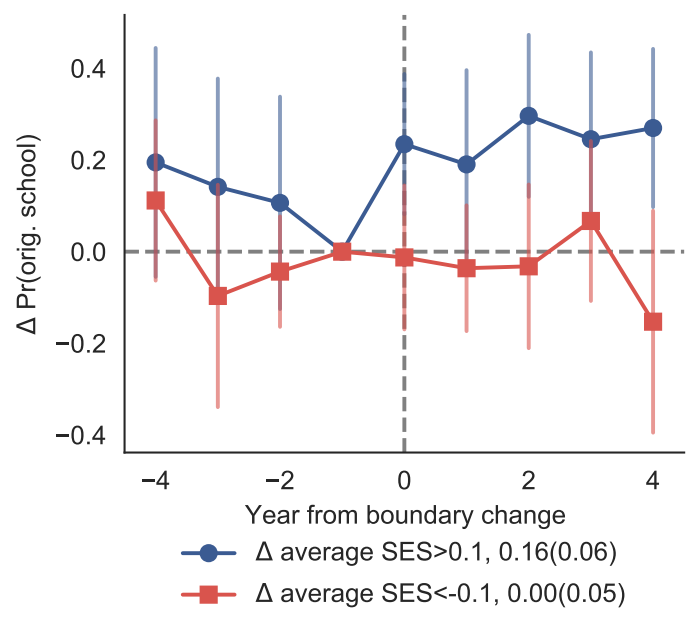

(b) Stay in original district school

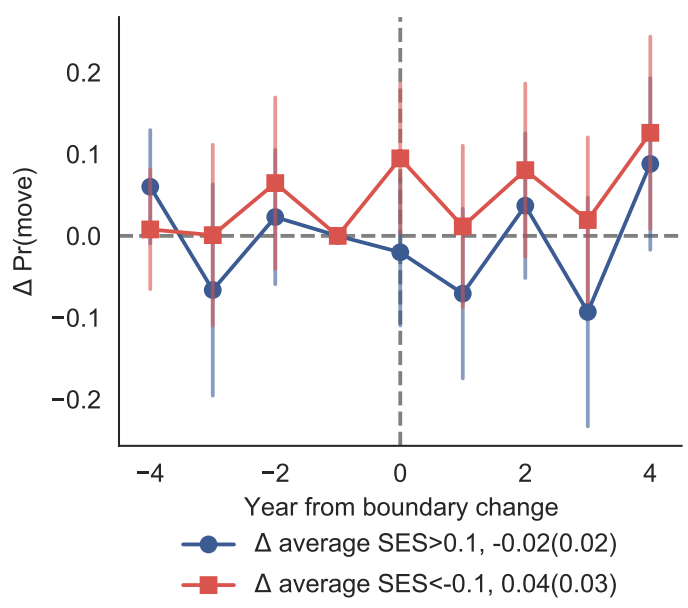

(d) Moving

Figure B.4: Response along margins to change in district by school characteristic

The figure display the interaction terms, $\beta_{-}^{k}$ and $\beta_{+}^{k}$, along with 95-percent confidence intervals. The parameters represent the difference in likelihood of enrolling in the new district school when the average SES at a school level changes relative to the average arrival probability following a district change. The dependent variables of all figures are binary and measured at age 7 based on the district at age 7 for address at age 5. The models are estimated with "origin-district"-year fixed effects. Standard errors are clustered on municipality. Results are centered at the year before the district change. Estimates from a simple before-after-DID are reported in the legends of figure $5 b$. 


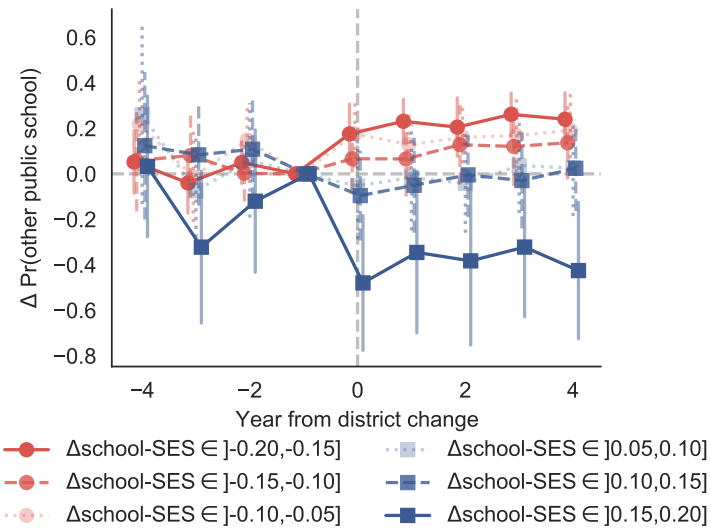

(a) Other public school

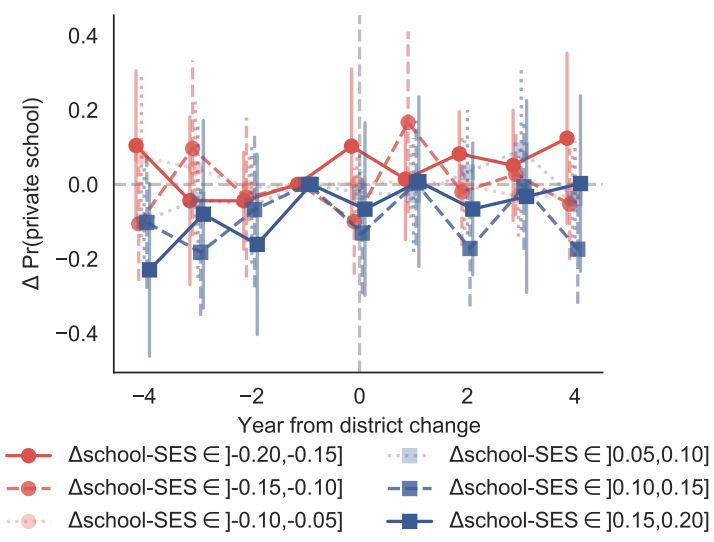

(c) Private school enrollment

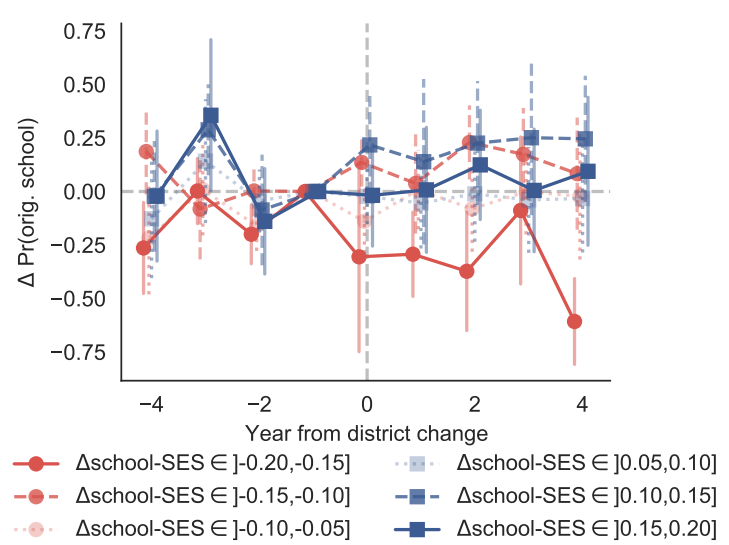

(b) Stay in original district school

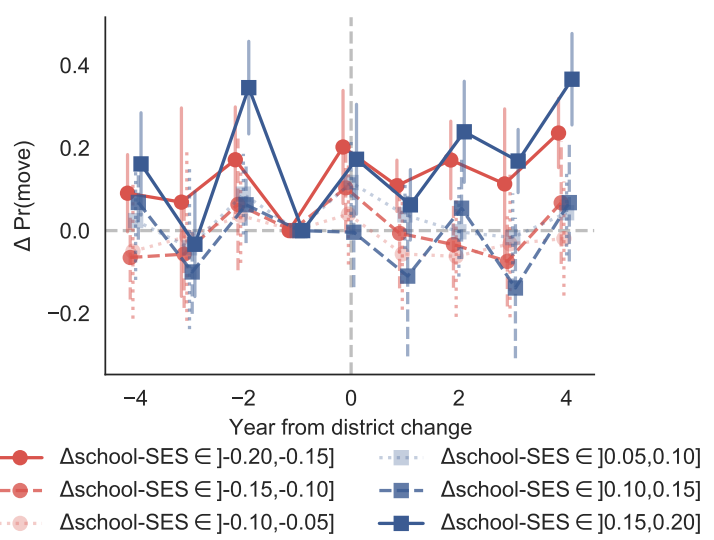

(d) Moving

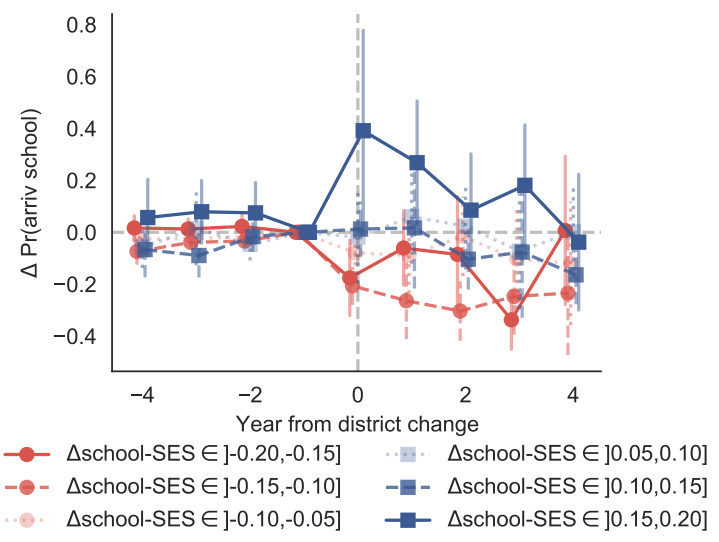

(e) Comply

Figure B.5: Response along margins to change in district by school characteristic, intensity of treatment

The figure display the a specification of the difference-in-difference model with varying levels of intensity, along with 95-percent confidence intervals. The parameters represent the difference in likelihood of enrolling in the new district school when the average SES at a school level changes relative to the average arrival probability following a district change. The reference school-SES change is between -0.05 and 0.05 . The dependent variables of all figures are binary and measured at age 7 based on the district at age 7 for address at age 5 . The models are estimated with "origin-district"-year fixed effects and o not control for distance. Standard errors are clustered on municipality. Results are centered at the year before the district change. Distance is not included as control. 
Table B.2: Compliance as a function of SAB change, full specification

\begin{tabular}{|c|c|c|c|c|c|}
\hline & (1) & (2) & (3) & (4) & $(5)$ \\
\hline Constant & $\begin{array}{l}0.01^{* * *} \\
(0.00)\end{array}$ & $\begin{array}{c}0.01^{* * *} \\
(0.00)\end{array}$ & $\begin{array}{c}0.01^{* * *} \\
(0.00)\end{array}$ & $\begin{array}{c}0.01^{* * *} \\
(0.00)\end{array}$ & $\begin{array}{c}0.01^{* * *} \\
(0.00)\end{array}$ \\
\hline $\mathrm{T}$ & $\begin{array}{l}-0.03^{* * *} \\
(0.00)\end{array}$ & $\begin{array}{c}-0.03^{* * *} \\
(0.00)\end{array}$ & $\begin{array}{c}-0.03^{* * *} \\
(0.00)\end{array}$ & $\begin{array}{c}-0.03^{* * *} \\
(0.00)\end{array}$ & $\begin{array}{c}-0.03^{* * *} \\
(0.00)\end{array}$ \\
\hline $\mathrm{T} \times$ Post & $\begin{array}{l}0.32^{* * *} \\
(0.01)\end{array}$ & $\begin{array}{c}0.33^{* * *} \\
(0.01)\end{array}$ & $\begin{array}{c}0.33^{* * *} \\
(0.01)\end{array}$ & $\begin{array}{c}0.29^{* * *} \\
(0.01)\end{array}$ & $\begin{array}{c}0.30^{* * *} \\
(0.01)\end{array}$ \\
\hline$\Delta$ Dist & $\begin{array}{l}0.00 \\
(0.00)\end{array}$ & $\begin{array}{c}0.00 \\
(0.00)\end{array}$ & $\begin{array}{c}0.00 \\
(0.00)\end{array}$ & $\begin{array}{c}0.01 \\
(0.01)\end{array}$ & $\begin{array}{c}0.00 \\
(0.01)\end{array}$ \\
\hline$\Delta$ Dist $\times$ Post & $\begin{array}{l}-0.05^{* * *} \\
(0.00)\end{array}$ & $\begin{array}{c}-0.05^{* * *} \\
(0.00)\end{array}$ & $\begin{array}{c}-0.05^{* * *} \\
(0.00)\end{array}$ & $\begin{array}{c}-0.08^{* * *} \\
(0.01)\end{array}$ & $\begin{array}{c}-0.07^{* * *} \\
(0.01)\end{array}$ \\
\hline$\Delta \mathrm{SES}$ & & $\begin{array}{c}-0.13^{* * *} \\
(0.03)\end{array}$ & & & $\begin{array}{c}-0.06 \\
(0.06)\end{array}$ \\
\hline$\Delta \mathrm{SES} \times$ Post & & $\begin{array}{c}0.72^{* * *} \\
(0.04)\end{array}$ & & & $\begin{array}{c}0.54^{* * *} \\
(0.08)\end{array}$ \\
\hline$\Delta \mathrm{NW}$ & & & $\begin{array}{c}0.10^{* * *} \\
(0.02)\end{array}$ & & $\begin{array}{c}0.07 \\
(0.04)\end{array}$ \\
\hline$\Delta \mathrm{NW} \times$ Post & & & $\begin{array}{c}-0.41^{* * *} \\
(0.03)\end{array}$ & & $\begin{array}{c}-0.22^{* * *} \\
(0.06)\end{array}$ \\
\hline$\Delta \mathrm{SVA}$ & & & & $\begin{array}{l}-0.00 \\
(0.01)\end{array}$ & $\begin{array}{l}-0.01 \\
(0.01)\end{array}$ \\
\hline$\Delta \mathrm{SVA} \times$ Post & & & & $\begin{array}{c}0.07^{* * *} \\
(0.01)\end{array}$ & $\begin{array}{c}0.11^{* * *} \\
(0.01)\end{array}$ \\
\hline $\mathrm{N}$ & 48,517 & 48,517 & 48,517 & 47,095 & 47,095 \\
\hline
\end{tabular}

Columns 1-3 display regression results for the model presented in Equation (3) for one school characteristic at a time and with compliance as dependent variable. Column 4 display the result of an estimation using all characteristics at a time. The models are estimated with "origin-attendance-zone"-year fixed effects. Standard errors are in parentheses and clustered on "origin-attendance-zone"-level.

Table B.3: Responses along different margins

\begin{tabular}{|c|c|c|c|c|c|}
\hline & Comply & Original & Third & Private & Move \\
\hline \multirow[t]{2}{*}{$\mathrm{T}$} & $-0.03^{* * *}$ & $-0.17^{* * *}$ & $0.16^{* * *}$ & $0.04^{* * *}$ & 0.00 \\
\hline & $(0.00)$ & $(0.01)$ & $(0.01)$ & $(0.01)$ & $(0.01)$ \\
\hline \multirow[t]{2}{*}{$\mathrm{T} \times$ Post } & $0.33^{* * *}$ & $-0.12^{* * *}$ & $-0.18^{* * *}$ & $-0.03^{*}$ & 0.01 \\
\hline & $(0.01)$ & $(0.02)$ & $(0.01)$ & $(0.01)$ & $(0.01)$ \\
\hline \multirow[t]{2}{*}{$\Delta$ Dist } & 0.00 & $0.04^{* *}$ & $-0.04^{* * *}$ & -0.00 & -0.00 \\
\hline & $(0.00)$ & $(0.01)$ & $(0.01)$ & $(0.01)$ & $(0.01)$ \\
\hline \multirow[t]{2}{*}{$\Delta$ Dist $\times$ Post } & $-0.05^{* * *}$ & 0.01 & $0.05^{* * *}$ & -0.02 & 0.01 \\
\hline & $(0.00)$ & $(0.02)$ & $(0.01)$ & $(0.01)$ & $(0.01)$ \\
\hline \multirow[t]{2}{*}{$\Delta \mathrm{SES}$} & $-0.13^{* * *}$ & $-0.62^{* * *}$ & $0.66^{* * *}$ & 0.03 & 0.06 \\
\hline & $(0.03)$ & $(0.09)$ & $(0.06)$ & $(0.07)$ & $(0.07)$ \\
\hline \multirow[t]{2}{*}{$\Delta$ SES $\times$ Post } & $0.72^{* * *}$ & $0.38^{* *}$ & $-0.79^{* * *}$ & $-0.21^{*}$ & -0.10 \\
\hline & $(0.04)$ & $(0.12)$ & $(0.08)$ & $(0.09)$ & $(0.09)$ \\
\hline $\mathrm{N}$ & 48517.00 & 48517.00 & 48517.00 & 48517.00 & 48517.00 \\
\hline
\end{tabular}

Columns display regression results for the model presented in Equation (3) using SES as a measure of schools with margins of response displayed in the columns title. The models are estimated with homogeneous compliance both in sign of change and household-SES. The models are estimated with 'origin-attendance-zone"-year fixed effects. Standard errors are in parentheses and clustered on origin 'origin-attendance-zone"-level. 
Table B.4: Responses along different margins to NW-share, interacted with own ethnicity

\begin{tabular}{llcccc}
\hline \hline & Comply & Original & Third & Private & Move \\
\hline $\mathrm{T} \times$ Post & $0.34^{* * *}$ & $-0.13^{* * *}$ & $-0.19^{* * *}$ & -0.02 & 0.01 \\
& $(0.01)$ & $(0.02)$ & $(0.01)$ & $(0.01)$ & $(0.01)$ \\
$\Delta \mathrm{Dist} \times$ Post & $-0.05^{* * *}$ & 0.00 & $0.05^{* * *}$ & -0.01 & 0.00 \\
& $(0.01)$ & $(0.02)$ & $(0.01)$ & $(0.01)$ & $(0.01)$ \\
$\Delta \mathrm{NW} \times$ Post & $-0.56^{* * *}$ & $-0.26^{*}$ & $0.68^{* * *}$ & -0.02 & $0.16^{*}$ \\
$\mathrm{~T} \times$ Post $\times \mathrm{NW}$ & $(0.03)$ & $(0.11)$ & $(0.07)$ & $(0.08)$ & $(0.08)$ \\
& -0.01 & 0.04 & 0.03 & -0.04 & -0.01 \\
$\mathrm{Dist} \times$ Post $\times \mathrm{NW}$ & $(0.01)$ & $(0.04)$ & $(0.02)$ & $(0.03)$ & $(0.03)$ \\
& 0.02 & 0.05 & $-0.07^{\dagger}$ & -0.05 & 0.05 \\
$\Delta \mathrm{NW} \times$ Post $\times \mathrm{NW}$ & $(0.02)$ & $(0.06)$ & $(0.04)$ & $(0.04)$ & $(0.04)$ \\
& $0.44^{* * *}$ & -0.09 & $-0.27^{*}$ & 0.05 & -0.12 \\
$\mathrm{~N}$ & $(0.06)$ & $(0.19)$ & $(0.12)$ & $(0.14)$ & $(0.13)$ \\
\hline \hline
\end{tabular}

Columns display regression results for the model presented in Equation (3) using SES as a measure of schools with different dependent variables, displayed in the columns title. Characteristics are interacted with household Non-Western dummy. The models are estimated with "origin-SAB"-year fixed effects. Standard errors are in parentheses and clustered on origin SAB level.

Table B.5: Compliance as a function of change educational composition, full specification

\begin{tabular}{|c|c|c|c|c|c|}
\hline & Comply & Original & Third & Private & Move \\
\hline \multirow[t]{2}{*}{$\mathrm{T}$} & -0.03 & -0.16 & 0.15 & 0.04 & -0.00 \\
\hline & $(0.00)$ & $(0.01)$ & $(0.01)$ & $(0.01)$ & $(0.01)$ \\
\hline \multirow[t]{2}{*}{$\mathrm{T} \times$ Post } & 0.33 & -0.13 & -0.18 & -0.03 & 0.01 \\
\hline & $(0.01)$ & $(0.02)$ & $(0.01)$ & $(0.01)$ & $(0.01)$ \\
\hline \multirow[t]{2}{*}{$\Delta$ Dist } & 0.00 & 0.05 & -0.04 & -0.00 & -0.01 \\
\hline & $(0.00)$ & $(0.01)$ & $(0.01)$ & $(0.01)$ & $(0.01)$ \\
\hline \multirow[t]{2}{*}{$\Delta$ Dist $\times$ Post } & -0.05 & 0.01 & 0.05 & -0.02 & 0.01 \\
\hline & $(0.00)$ & $(0.02)$ & $(0.01)$ & $(0.01)$ & $(0.01)$ \\
\hline \multirow[t]{2}{*}{$\triangle \mathrm{EDUC}$} & -0.16 & -0.77 & 0.93 & 0.09 & -0.08 \\
\hline & $(0.05)$ & $(0.15)$ & $(0.09)$ & $(0.11)$ & $(0.11)$ \\
\hline \multirow[t]{2}{*}{$\Delta \mathrm{EDUC} \times$ Post } & 0.97 & 0.38 & -0.99 & -0.40 & 0.03 \\
\hline & $(0.06)$ & $(0.20)$ & $(0.12)$ & $(0.14)$ & $(0.14)$ \\
\hline $\mathrm{N}$ & 48,517 & 48,517 & 48,517 & 48,517 & 48,517 \\
\hline
\end{tabular}

Columns display regression results for the model presented in Equation (3) using average share of parents with loncg.cycle education as a measure of schools with margins of response displayed in the columns title. The models are estimated with "origin-attendance-zone"-year fixed effects. Standard errors are in parentheses and clustered on origin 'origin-attendance-zone"-level. The full output of the top panel can be found in Appendix Table B.3. Remaining output available upon request. 
Table B.6: Compliance as a function of change in average income, full specification

\begin{tabular}{llcccc}
\hline \hline & Comply & Original & Third & Private & Move \\
\hline $\mathrm{T} \times$ Post & 0.32 & -0.13 & -0.13 & -0.04 & -0.02 \\
$\mathrm{~T} \times$ Post $\times$ INC Q2 & $(0.01)$ & $(0.03)$ & $(0.02)$ & $(0.02)$ & $(0.02)$ \\
& 0.03 & 0.01 & -0.06 & -0.01 & 0.03 \\
$\mathrm{~T} \times$ Post $\times$ INC Q3 & $(0.01)$ & $(0.04)$ & $(0.03)$ & $(0.03)$ & $(0.03)$ \\
$\mathrm{T} \times$ Post $\times$ INC Q4 & 0.03 & -0.01 & -0.12 & 0.02 & 0.09 \\
& $(0.01)$ & $(0.04)$ & $(0.03)$ & $(0.03)$ & $(0.03)$ \\
$\Delta$ Dist $\times$ Post & 0.02 & 0.00 & -0.04 & 0.01 & 0.00 \\
& $(0.01)$ & $(0.04)$ & $(0.02)$ & $(0.03)$ & $(0.03)$ \\
$\Delta$ Dist $\times$ Post $\times$ INC Q2 & -0.04 & 0.04 & 0.02 & -0.01 & -0.01 \\
& $(0.01)$ & $(0.03)$ & $(0.02)$ & $(0.02)$ & $(0.02)$ \\
$\Delta$ Dist $\times$ Post $\times$ INC Q3 & -0.02 & -0.01 & 0.05 & -0.03 & 0.01 \\
& $(0.01)$ & $(0.04)$ & $(0.02)$ & $(0.03)$ & $(0.03)$ \\
$\Delta$ Dist $\times$ Post $\times$ INC Q4 & 0.00 & -0.05 & 0.04 & -0.01 & 0.02 \\
& $(0.01)$ & $(0.04)$ & $(0.02)$ & $(0.03)$ & $(0.03)$ \\
$\Delta I N C_{s}$ & -0.03 & -0.06 & 0.05 & 0.04 & 0.00 \\
$\Delta I N C_{s} \times$ INC Q2 & $(0.01)$ & $(0.04)$ & $(0.02)$ & $(0.03)$ & $(0.03)$ \\
$\Delta I N C_{s} \times$ INC Q3 & 0.57 & 0.67 & -0.84 & -0.17 & -0.23 \\
$\Delta I N C_{s} \times$ INC Q4 & $(0.08)$ & $(0.25)$ & $(0.16)$ & $(0.18)$ & $(0.18)$ \\
$\mathrm{N}$ & 0.40 & -0.57 & -0.17 & -0.13 & 0.47 \\
\hline \hline
\end{tabular}

Columns display regression results for the model presented in Equation (3) using average income as a measure of schools with margins of response displayed in the columns title. Models are estimated with heterogeneity in responses for household-income quartiles where the first quartile is the baseline. The models are estimated with "origin-attendance-zone"-year fixed effects. Standard errors are in parentheses and clustered on origin 'originattendance-zone"-level. The full output of the top panel can be found in Appendix Table B.3. Remaining output available upon request. 


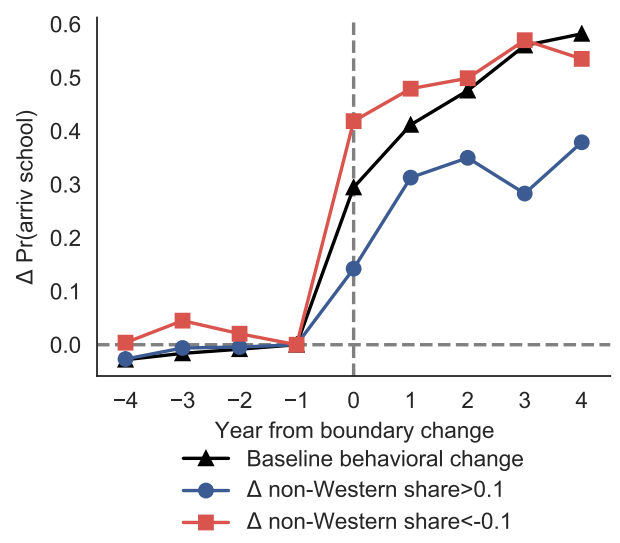

(a) NW - aggregate compliance

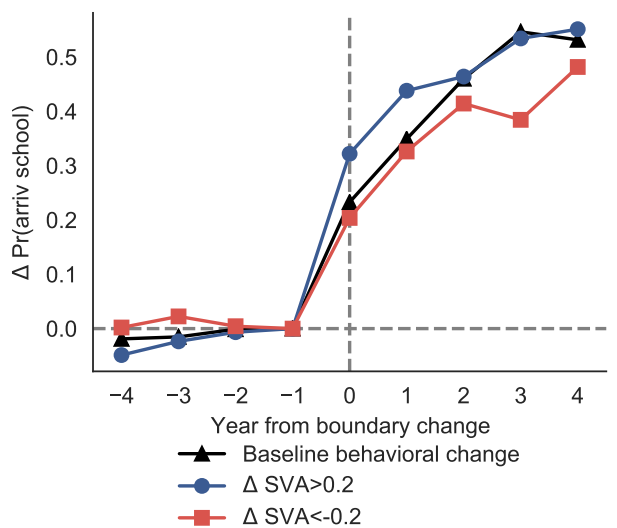

(c) SVA - aggregate compliance

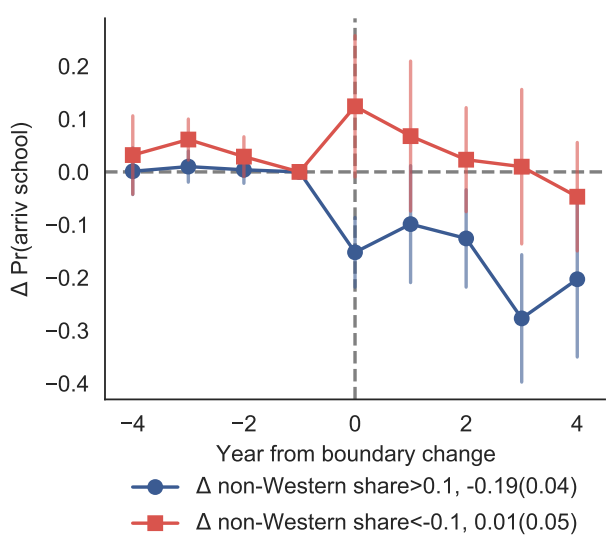

(b) NW-share - interaction

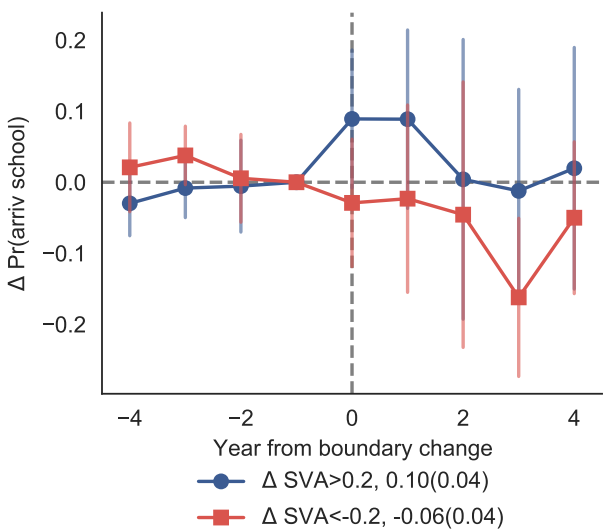

(d) SVA - interaction

Figure B.6: Compliance as a function of Non-Western share and school value-added

The figures on the left display changes in estimated compliance rates based on the model in (2) estimated with differnent measures of school characteristics. The black lines depict the estimated $\beta_{T}^{k} \mathrm{~s}$, while the blue and red line depict $\beta_{T}^{k}+\beta_{-}^{k}$ and $\beta_{T}^{k}+\beta_{+}^{k}$ respectively. The figures to the right display the interaction terms, $\beta_{-}^{k}$ and $\beta_{+}^{k}$, along with 95 -percent confidence intervals. The parameters represent the difference in likelihood of enrolling in the new district school when the school characteristic at a school level changes relative to the average arrival probability following a district change. The dependent variable is binary and equals one if the child is enrolled in the district school at age 7 based on the district at age 7 for address at age 5 . The y-axis denotes the excess probability of enrolling relative to baseline. Standard errors are clustered on municipality. Results are centered at the year before the district change. Estimates from a simple before-after-DID are reported in the legends of figure $5 \mathrm{~b}$. 


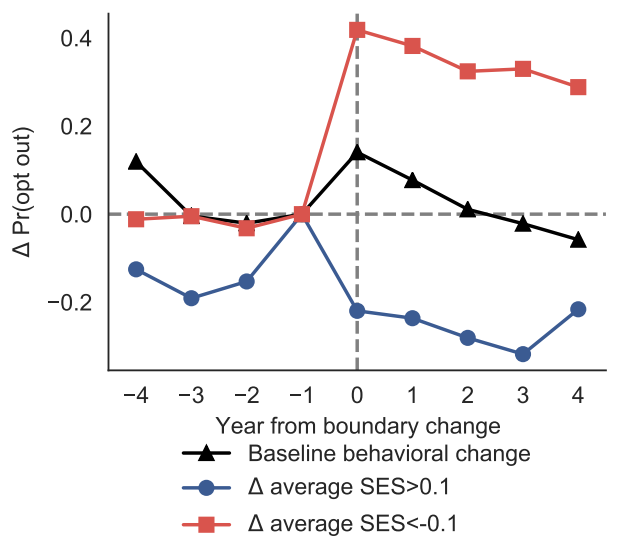

(a) Agg. non-compliance

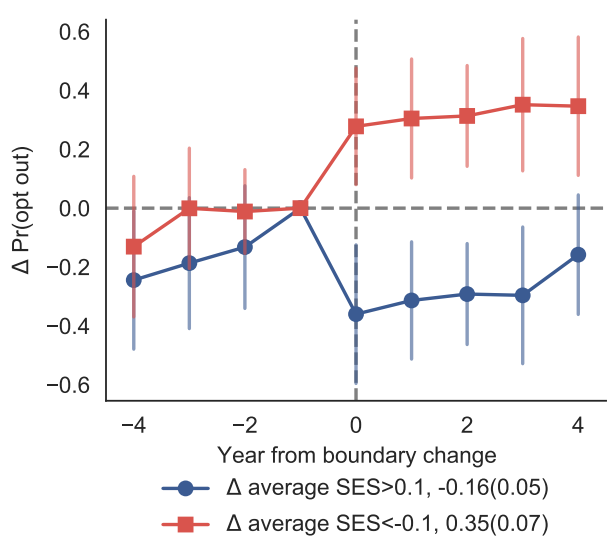

(b) Interaction parameters

Figure B.7: Alternative definition of opting out, School-SES

The figure display the interaction terms, $\beta_{-}^{k}$ and $\beta_{+}^{k}$, along with 95-percent confidence intervals. The parameters represent the difference in likelihood of opting out of designated school at age 7 when the average SES at a school level changes relative to the average arrival probability following a district change. The dependent variableis binary and measured at age 7 based on the district at age 7 for address at age 5 . The model is estimated with "origin-district"-year fixed effects. Standard errors are clustered on origin district level. Results are centered at the year before the district change. Estimates from a simple before-after-DID are reported in the legend. 
Table B.7: Alternative compliance as a function of SAB change - split by matching

\begin{tabular}{|c|c|c|c|c|c|}
\hline & (1) & (2) & (3) & (4) & (5) \\
\hline & \multicolumn{5}{|c|}{ - Subsample: Unmatched sample - } \\
\hline $\mathrm{T} \times$ Post & $\begin{array}{c}0.15 \\
(0.02)\end{array}$ & $\begin{array}{c}0.13 \\
(0.02)\end{array}$ & $\begin{array}{c}0.14 \\
(0.02)\end{array}$ & $\begin{array}{c}0.16 \\
(0.02)\end{array}$ & $\begin{array}{c}0.15 \\
(0.02)\end{array}$ \\
\hline$\Delta$ Dist $\times$ Post & $\begin{array}{c}0.09 \\
(0.02)\end{array}$ & $\begin{array}{c}0.08 \\
(0.02)\end{array}$ & $\begin{array}{c}0.08 \\
(0.02)\end{array}$ & $\begin{array}{c}0.14 \\
(0.03)\end{array}$ & $\begin{array}{c}0.12 \\
(0.03)\end{array}$ \\
\hline$\Delta \mathrm{SES} \times$ Post & & $\begin{array}{l}-1.54 \\
(0.13)\end{array}$ & & & $\begin{array}{l}-2.08 \\
(0.32)\end{array}$ \\
\hline$\Delta \mathrm{NW} \times$ Post & & & $\begin{array}{c}0.89 \\
(0.09)\end{array}$ & & $\begin{array}{l}-0.36 \\
(0.24)\end{array}$ \\
\hline$\Delta \mathrm{SVA} \times$ Post & & & & $\begin{array}{c}0.01 \\
(0.04)\end{array}$ & $\begin{array}{l}-0.03 \\
(0.05)\end{array}$ \\
\hline \multirow[t]{2}{*}{$\mathrm{N}$} & 48,517 & 48,517 & 48,517 & 47,095 & 47,095 \\
\hline & \multicolumn{5}{|c|}{ - Subsample: Matched sample- } \\
\hline $\mathrm{T} \times$ Post & $\begin{array}{c}0.24 \\
(0.01)\end{array}$ & $\begin{array}{c}0.25 \\
(0.01)\end{array}$ & $\begin{array}{c}0.25 \\
(0.01)\end{array}$ & $\begin{array}{c}0.19 \\
(0.02)\end{array}$ & $\begin{array}{c}0.18 \\
(0.02)\end{array}$ \\
\hline$\Delta$ Dist $\times$ Post & $\begin{array}{c}0.07 \\
(0.00)\end{array}$ & $\begin{array}{c}0.07 \\
(0.00)\end{array}$ & $\begin{array}{c}0.07 \\
(0.00)\end{array}$ & $\begin{array}{c}0.20 \\
(0.02)\end{array}$ & $\begin{array}{c}0.22 \\
(0.02)\end{array}$ \\
\hline$\Delta \mathrm{SES} \times$ Post & & $\begin{array}{l}-0.48 \\
(0.10)\end{array}$ & & & $\begin{array}{l}-1.53 \\
(0.24)\end{array}$ \\
\hline$\Delta \mathrm{NW} \times$ Post & & & $\begin{array}{c}0.30 \\
(0.07)\end{array}$ & & $\begin{array}{l}-0.52 \\
(0.17)\end{array}$ \\
\hline$\Delta \mathrm{SVA} \times$ Post & & & & $\begin{array}{l}-0.06 \\
(0.04)\end{array}$ & $\begin{array}{l}-0.08 \\
(0.04)\end{array}$ \\
\hline $\mathrm{N}$ & 141,765 & 141,765 & 141,765 & 138,072 & 138,072 \\
\hline
\end{tabular}

This table shows the coefficient of the model in Equation (3) where the alternative compliance measure, enrollment in designated school at age 7, as the dependent variable. It uses both the full/unmatched and the matched sample where children outside of the district are used as controls. Details of the matching procedure is found in Subsection 5.4 under the heading "Spillovers to untreated". Columns 2-4 display regression results for the model presented in Equation (3) for one school characteristic at a time. Column 5 displays the result of an estimation using all characteristics at a time. The models are estimated with "origin-attendance-zone"-year fixed effects. Standard errors are in parentheses and clustered on by actual and matched municipality. 


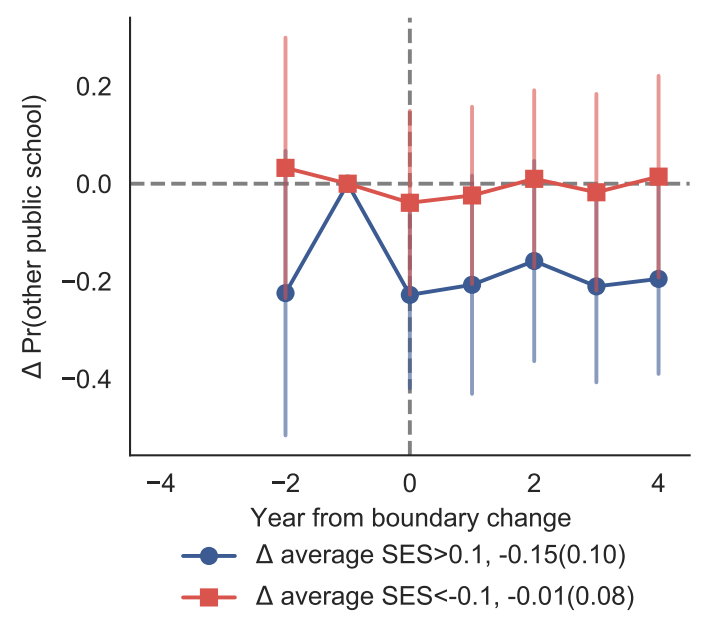

(a) Other public school

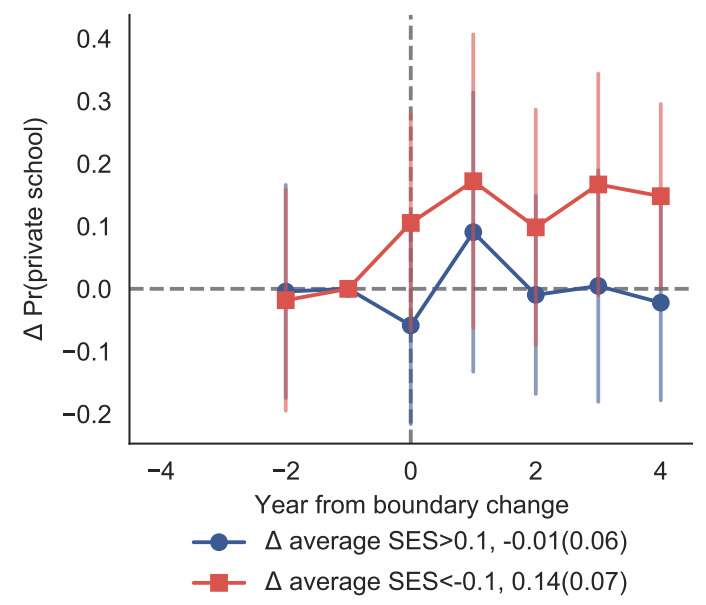

(c) Private school enrollment

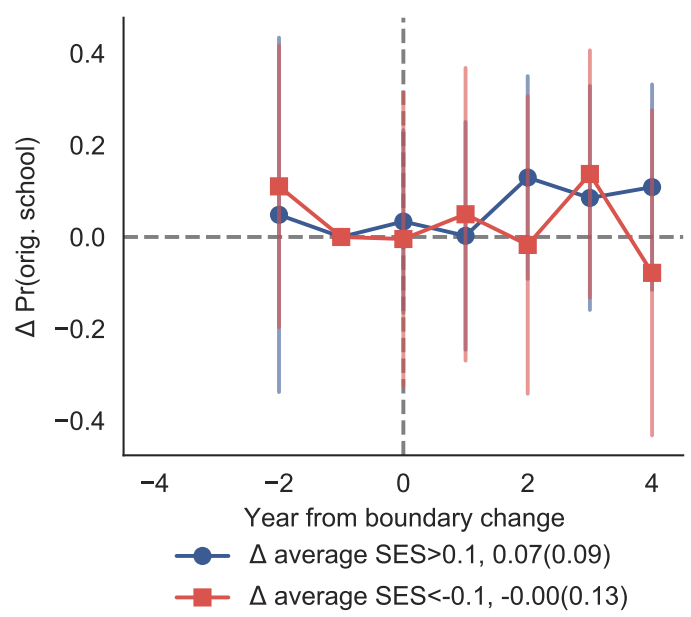

(b) Stay in original district school

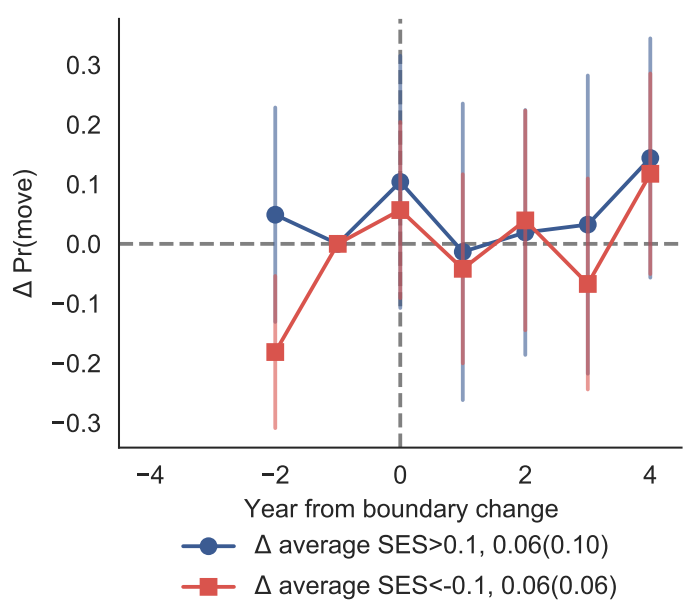

(d) Moving

Figure B.8: Response along margins to change in district by school characteristic when child aged 3 at time of boundary change

The figure display the interaction terms, $\beta_{-}^{k}$ and $\beta_{+}^{k}$, along with 95-percent confidence intervals. The parameters represent the difference in likelihood of enrolling in the new district school when the average SES at a school level changes relative to the average arrival probability following a district change. The dependent variables of all figures are binary and measured at age 7 based on the district at age 7 for address at age 3 . The models are estimated with "origin-district"-year fixed effects. Standard errors are clustered on origin district level. Results are centered at the year before the district change. 